\title{
Designing an Eelectronic Transmission System Using the Information and Communication Technology Infrastructure "A Proposed Model for the Intranet at the University of Mosul"

\author{
Raed A. Al-Dabbagh \\ Mustafa Z. Al-Dabbagh \\ College of Administration and Economics \\ University of Mosul, Mosul, Iraq
}

\section{Received on: 09/06/2011}

Accepted on: 03/10/2011

\section{ABSTRACT}

The aim of the current study is to employing ICT in a way that supports management by establishing an electronic transmission system characterized with some features different from the previous ones through depending on open source programs which give the ability of continuous development without any costs. In addition, this system also has additional features such as operating under different operating systems.

This proposed model consists of two programs. The first one is an e-mail server provides a number of features and characteristics. The second program enables the user to apply some of the features for mailing data with big size, with high speed and secured depending on the internal mailing system (intranet) of Mosul University.

The system provides a special account with a password for each user on the services network and can also provide some features represented in stopping the undesired e-mails, checking the inbox and making sure that it is empty of viruses, resend some received e-mails for unlimited number of users on the same network, in addition to doing its normal tasks of sending and receiving e-mails; such as (writing a letters, editing and deleting). These programs can be downloaded from the internet for free and without any cost.

Keywords: Information and communication technology, electronic transmission system, Open source programs.

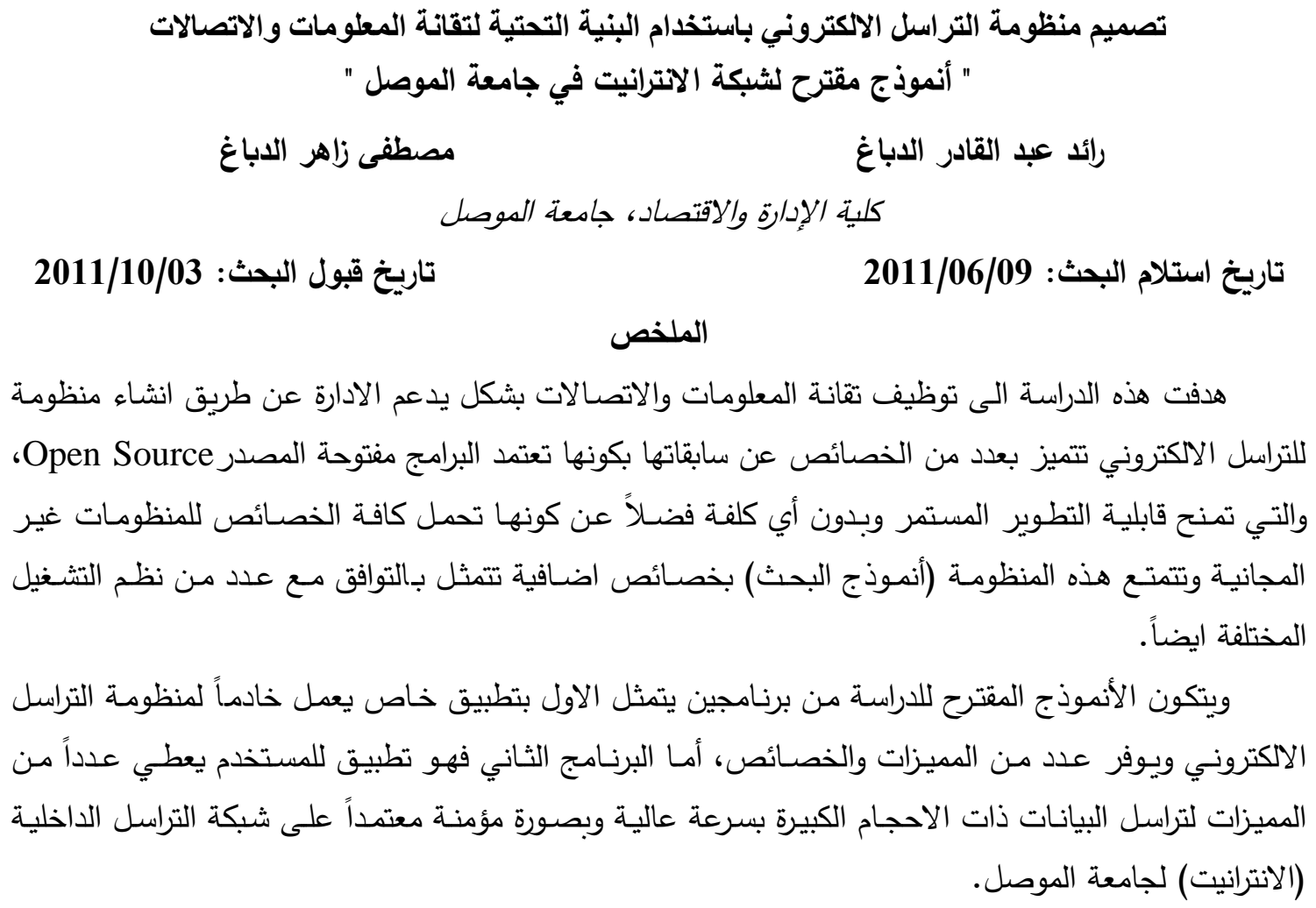


ويوفر النظام بذلك حساباً خاصاً مع كلمة مرور لكل مستخدم على الثبكة ويتيح عدداً من الخصائص تتمثل بإيقاف الرسائل غير المرغوب بها، فحص البريد الوارد والتأكد من خلوه من الفايروسات، اعادة ارسال الرسائل

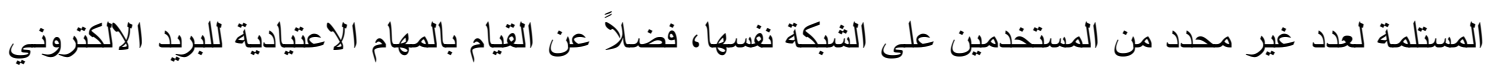

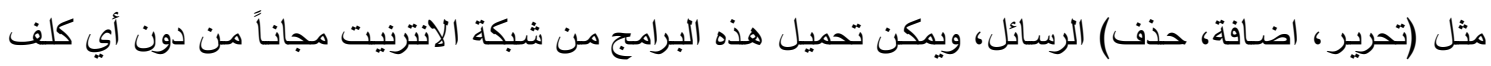
مادية. الكلمات المفتاحية: تقانة المعلومات والاتصالات، منظومة التراسل الاكتروني، البرامج مفتوحة المصدر.

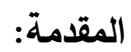
تعد منظومات التراسل الاككتروني بأنواعها المختلفة حديثة العهد اذ تطورت هذه النظم في العقدين الاخيرين

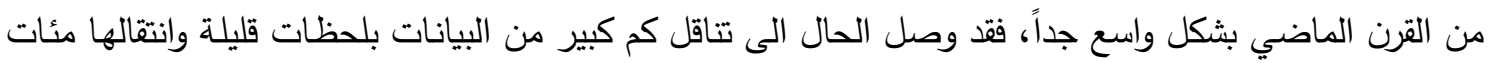
الالالف من الاميال وذلك بفضل التطور الهائل في تقانات المعلومات والاتصـالات فضـلاً عن انتشار التطبيقات الحديثة وزيادة الوعي للى المجتمع بكيفية استخدام وتوظيف هذه التقانـة لأنجاز الوظائف اليومية الروتينية منها والمعقدة ايضاً.

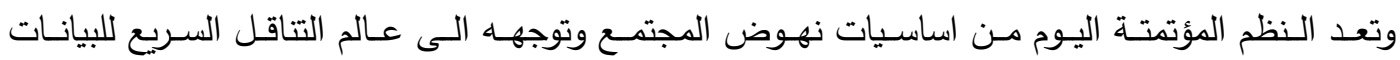
والمعلومات واللحاق بركاب ما يسمى بعصر السرعة، اذ ان نظم التراسل الاككتروني ومن امثلتها البريد الالكتروني

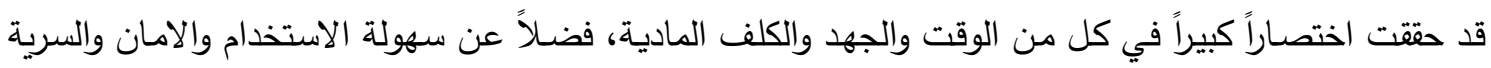
التي تؤمنها تلك النظم. ولمـا كانت انظمة الاتصـالات في العـالم هي من اهم المقومات التي تستتد عليها الغالبيـة العظمى من

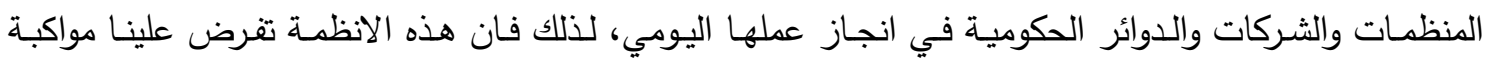

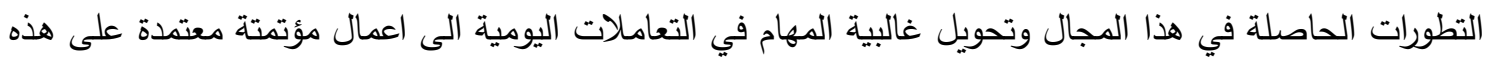

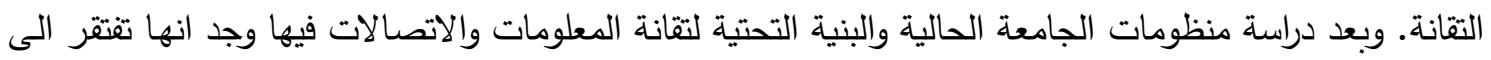
منظومة اتصال خالية من التكاليف معتمدة على برامجيات مفتوحة المصدر Open Source ومعدومة الثغرات ولتأمين خط نقل وتراسل داخلي للبيانات والمعلومات مؤمن بصورة جيدة دفعنا الى انجاز البحث الحالي الذي لئي تمخض اسلوب حل لهذه المشكلة.

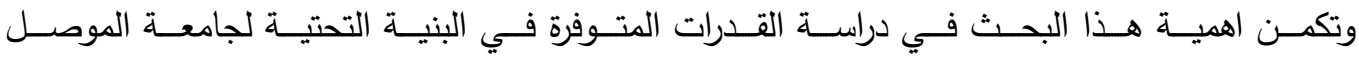
والامكانـات التي يمكن استخلاصـها عن طريتق إغنـاء تلك البنيـة التحتيـة لتقانـات المعلومـات والاتصـالات فيها بتطبيقـات خاليـة مـن التكاليف وقابلـة لـلادارة والعهـل بطاقتهـا القصــى والاسـتثمار الامثل لتقانـات المعلومـات والاتصالات والاستفادة من النظم الحديثة لهذة التقانات لرفع المستوى العلمي والوعي الثقافي لدى الافراد لإنجاز

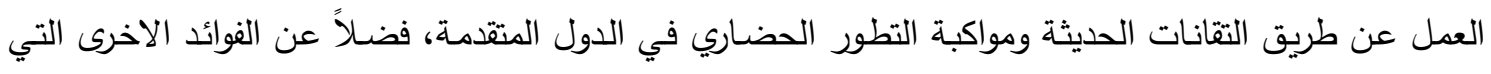
تتمثل بتقليل الكلف، الاعتماد على الموارد الداخلية، وتبني فكرة الحداثة في العمل عن طريق اتمتة الاعمال اليدوية،

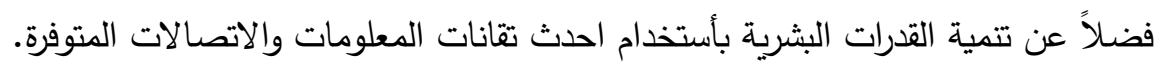

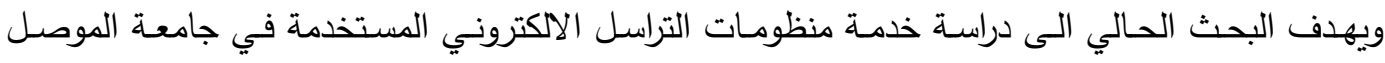

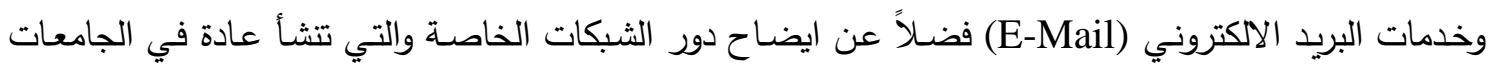
والدوائر الحكومية والتي تكون بمثابة بوابة نقل بمستوى عالٍ من السرية والموثوقية للبيانات والمعلومات، إذ يكمن

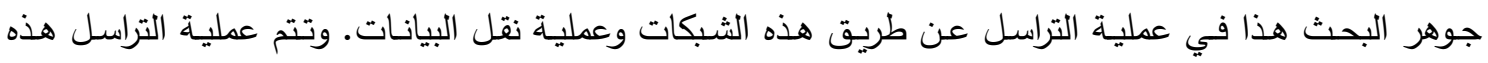


بأستخدام رسائل البريد الاككتروني ونقل الوثائق والصور وملفات الوسائط المتعددة (الصوت، الفيديو) بين الحواسيب

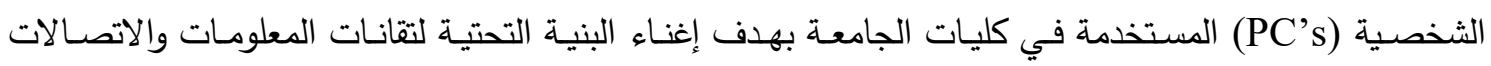
ببرامج حديثة مفتوحة المصدر • لقد تمثلت ادوات الدراسة بتطبيقين اساسيين، الاول هو برنامج الخادم (Mercury Server) الذي تم تهيئته

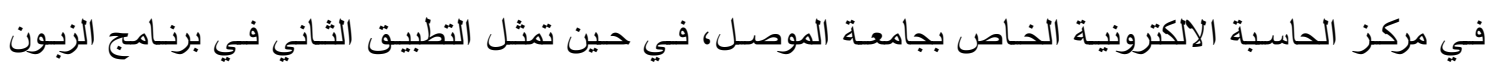
الذي تم تحميله في الحواسيب الخاصة بالمستخدمين، وتمتاز هذه التطبيقات بكونها قابلة للتحميل مجاناً من مواقعها على الثبكة العنكبوتية (الويب)، فضلاً عن تحميل التحديثات الخاصة بتلك البرامج من دون أي تكاليف اضافية وبصورة مستمرة. الجانب النظري

أولاً: تقانة المعلومات والاتصالات Information \& Communication Technology (ICT) لقــ اصـبح التأثير الايجـابي لتقانــة المعلومـات والاتصـالات، واضـــاً في اجـراءات وخـدمات مؤسسـات

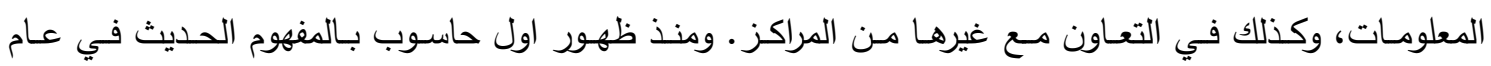

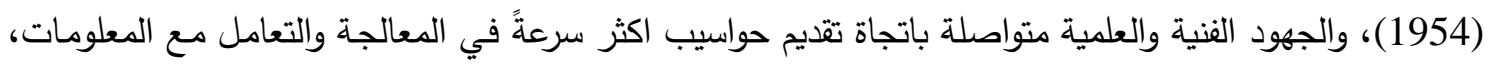

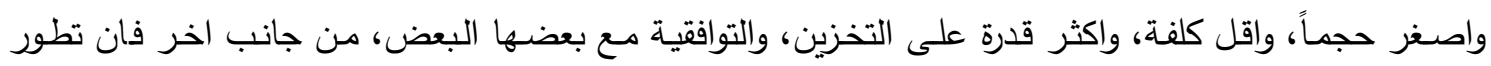

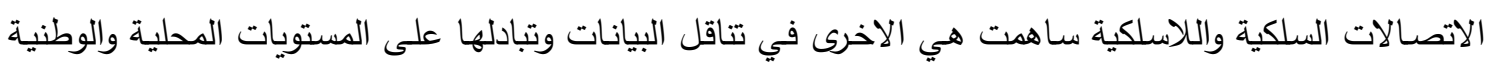

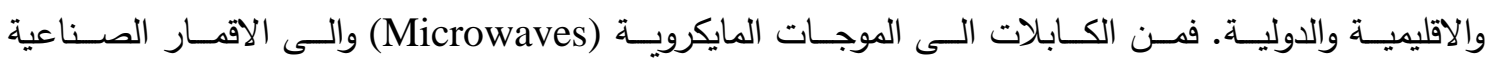
(Satellites)، ثم الى الالياف الضوئية (Fiber Optics) والوسائل الاخرى التي تستطيع نقل عشروات الملايين من الكلمات عبر المحيطات، ذهاباً واياباً، في دقيقة واحدة [3aئة (3).

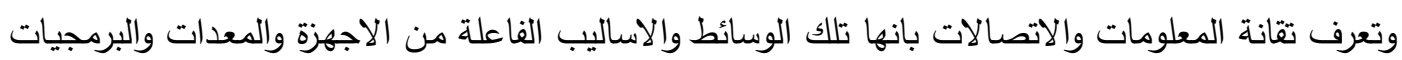
وادارة قواعد البيانات، التي تهدف الى جمع ومعالجة البيانات وخزن واسترجاع المعلومات وتجهيزها وتوصيلها من

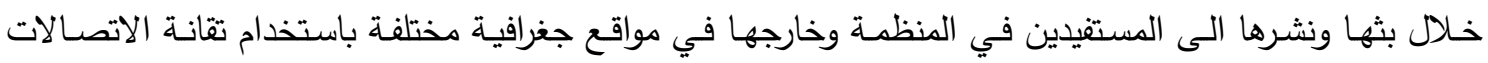

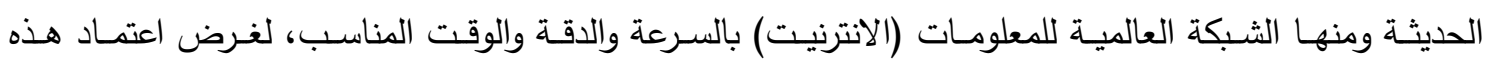

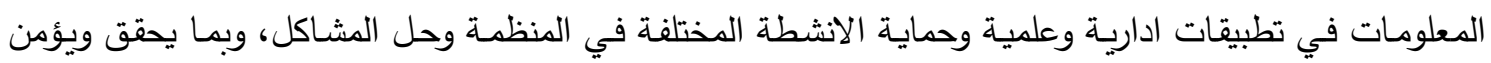
الاستخدام الصحيح لهذه المعلومات[4]. ومصطلح الحما عرفه موقع المصطلحات التكنولوجية يمثل التقانات التي توفر الوصول إلى المعلومات من خلا الاتصالات السلكية واللاسلكية. وهي مشابهة لتقانة المعلومات، لكنها تركز في المقام الأول على تقانات

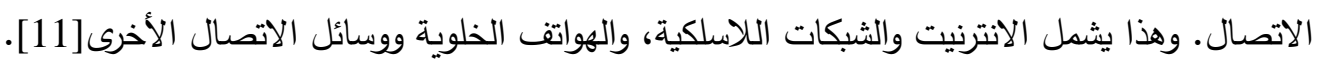
وترى الطائي [1] ان تقانة المعلومات والاتصالات بالاعتماد على المكونات (الاجهزة والمعدات، البرامجيات،

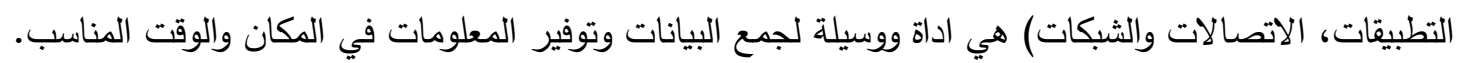

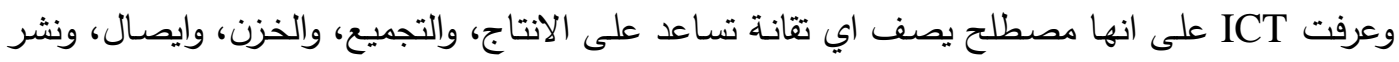
المعلومات. وتدمج هذه التقانة بين الحوسبة والاتصالات عالية السرعة لتضمين ونقل البيانات، والصوت، والصوته الصورة والفيديو معاً في اطار واحد [5]. 
كما اورد موقع ويكي الكتب بان تقانة المعلومات والاتصالات عبارة عن مجموعة متتوعة من الأدوات التقنية

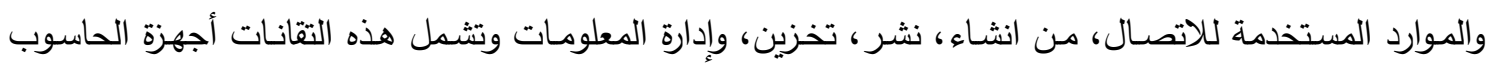

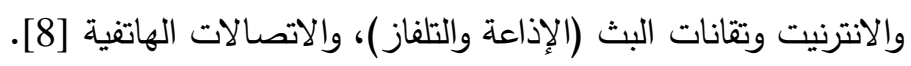

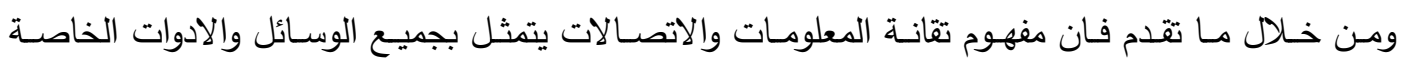

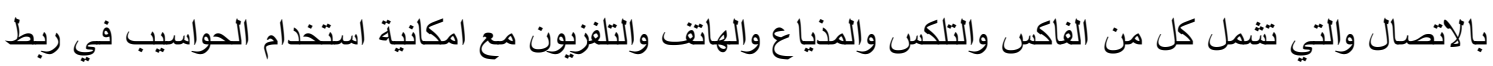

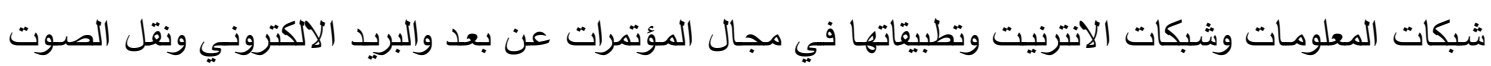

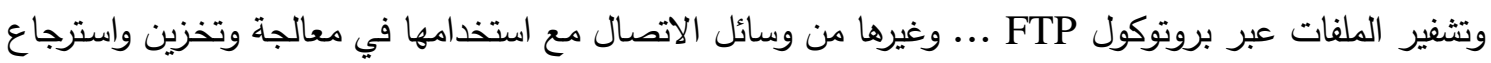
المعلومات عن طريق التكامل بين اجهز الحواسيب ونظم الاتصالات الحديثة. ثانياً: منظومات التراسل عبر البريد الاكتروني ان منظومات التراسل الالكتروني تقوم بعملية تبادل المعلومات بشكل الكتروني موثق ومصدق عن طريق

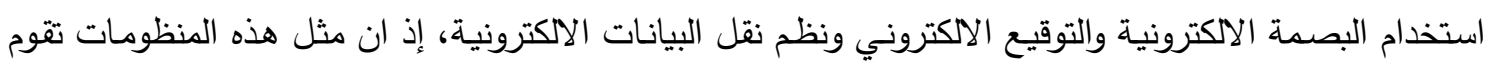

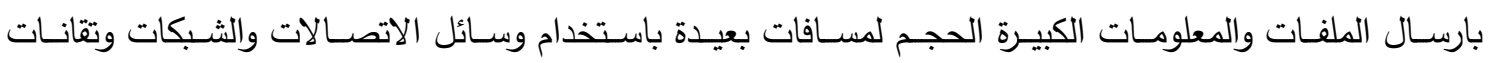
المعلومات، وادت هذه الانظمـة الى اختصـار في الوقت والجهد لدى الانسـان واصبح بمقدوره التوصل الى اي

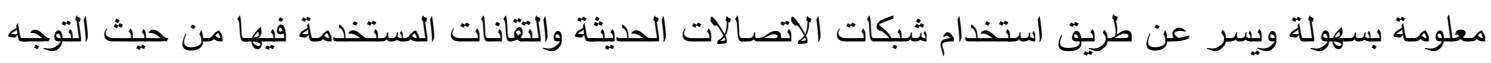
الى الشبكة العالمية (الانترنيت) والاكسترانت والشبكات الداخلية مثل شبكات الانترانيت والشبكات المحلية الخاصـة

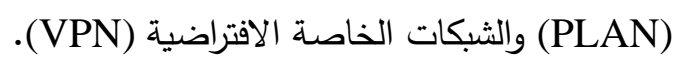

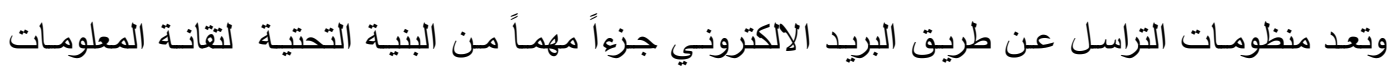
والاتصـالات في المنظمة إذ ان السبب المهم والاساسي لانشاء منظومـة للتراسل الداخلي في المنظمـة هو التحكم والامان لعملية نقل الوثائق داخل المنظمة الواحدة والتي تتكون من فروع عدة عوضاً عن السرعة في عملية النقل

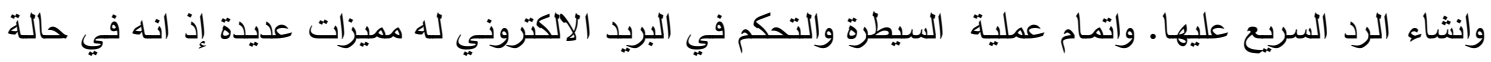

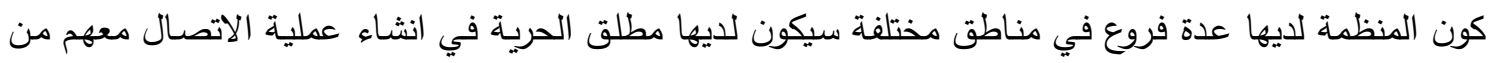

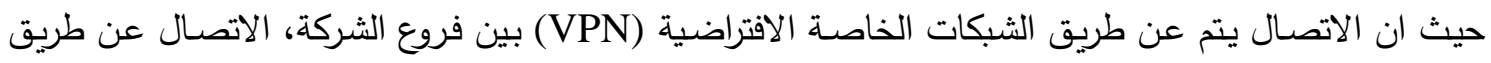

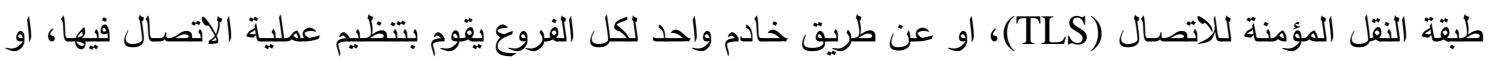

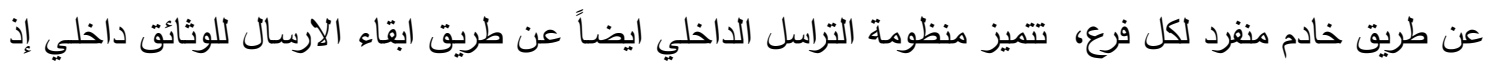
يتم نقل الرسائل والوثائق من طرف او من فرع الى اخر من دون ان تتتقل عن طريق مجهز خدمة خارجي (ISP)

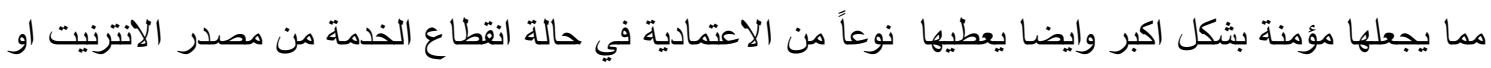

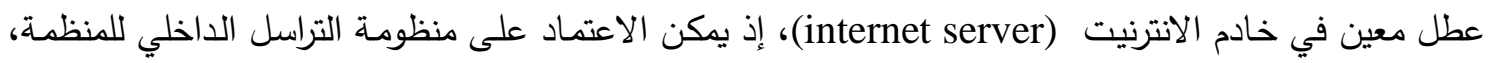
عوضاً عن السرعة وتجنباً لتأخير العمل الذي يحصل في منظومات التراسل التقليدية، فضلاً عن ان وسائط خزن التهن

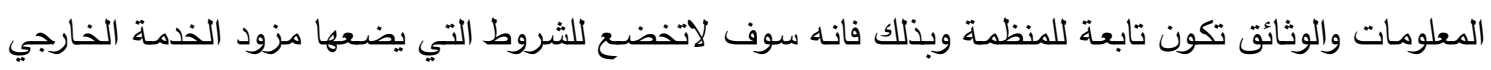
بتحديد عدد الرسـائل في صندوق البريد الواحد او سعة البريد من حيث الحجم إذ إن ان المنظمـة تستطيع ارسـال الرسالة بالمواصفات التي تحتاج اليها وفضلاً عن كون المنظمة سوف تكون المسؤولة عن الخادم إذ تستطيع وضع التعاتِ

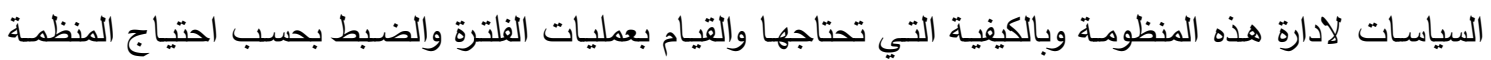




\section{المشاكل والمعوقات في منظومات التراسل التقليدية}

توجد مجموعة من الصعوبات والمشاكل في انجاز الاعمال عن طريق منظومات التراسل التقليدية ومن

$$
\text { ابرز هذه المشاكل والصعوبات [6]: }
$$

1. الوقت والجها والتكلفة المرتفعة لإنجاز العمل الورقي التقليدي.

2. صعوبة استرجاع الوثائق وما بها من معلومات.

3. البحث وحيد المدخل وعدم القدرة على البحث متعدد المداخل.

4. صعوبة إطلاع أكثر من موظف على المعاملة نفسها في الوقت نفسه.

5. عدم وجود آلية لمتابعة سير العمل.

6. عدم توحيد وتقنين أسلوب العمل في معالجة البريد الوارد والصـادر والمتابعة بين وحدات الجامعـة المختلفة

المتمثلة في الكليات والعمادات المساندة والمراكز البحثية والعلمية والإدارات.

7. كفاءة متدنية في أداء الأعمال.

8. تعقيد في تتفيذ معالجة البريد الوارد والصادر ومتابعة البريد الوارد الذي يتطلب رداً عليه.

9. صعوبة تحديد المخطئ والمسؤول عن تأخير العمل ومكافأة المتميز .

مميزات التراسل الاكتروني

وبعد توضيح هذه العقبات جميعها ينبغي علينا ايجاد صيغ حل لهذه المشاكل التي توالى ظهورها في عهد

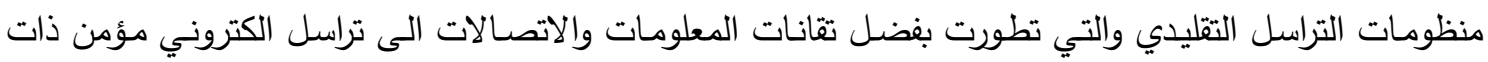

خصائص ومميزات عديدة والتي اهمها][2]

1. عدم التقيد بظروف المكان والزمان اي انه لا داعي لاستدعاء جهاز الثخص المطلوب الاتصال به للاستقبال،

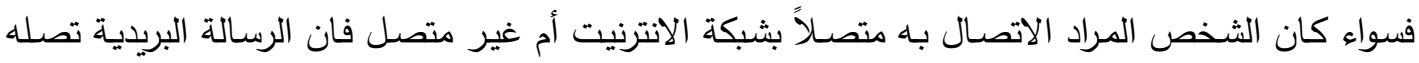

وحين دخوله (login) إلى الثبكة يقوم بقراءتها.

2. لا ضرورة لمراعاة فروق التوقيت (الزمن) والأبعاد الجغرافية (المسافة)، فإذا أرسل (شخص في الوطن العند العربي)

على سبيل المثال رسالة إلكترونية إلى (شخص اخر في المملكة المتحدة) فكل ما عليه هو معرفة عنوان البريد الإكتروني ثم الضغط بالماوس على زر إرسال (send) فتصبح الرسالة جاهزة للاستلام في جهاز الشركة المقدمة لخدمة الانترنيت او الخادم الخاص بالثركة في حالة الثبكات الداخلية والتي يتعامل معها ومن ثم بـ يقوم بقراءتها حين الاخول الى بريده الثخصي. 3. قليل التكلفة إذ إن تكلفة إرسال رسالة إلكترونية لا تزيد عن تكلفة الاتصال بمزود الخدمة فلا تحتاج لطوابع

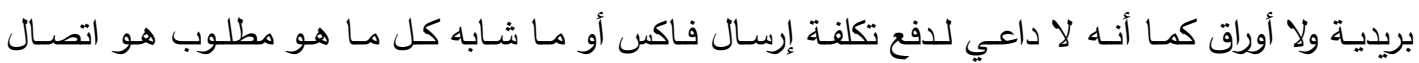
بالانترنيت وطريقة للوصول لصندوق البريد inbox وتتمثل غالباً ببرنامج البريد الإلكتروني أو نوعه.

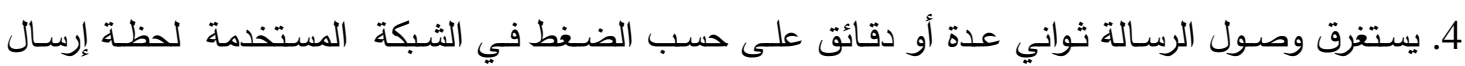
الرسالة.

5. تعدد المواد التي يتم نقلها عبر البريد الإككتروني مما يميز البريد الإكتروني عن البريد التقليدي هو امكانية نقل

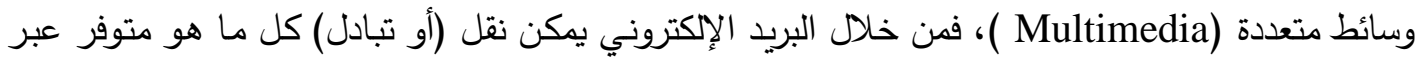
(texts, graphics, audio, الانترنيت او الانترانيت ومنها النصوص والصور والمواد السمعية والبصرية 
يتم ذلك من خلال البريد (mp3, mpeg, pdf, doc, rar, txt, zip) أو ملفات بصيخ متعددة منها video) الإلكتروني إما بواسطة صفحه البريد الإككتروني بشكل مباشر أو استخدام المرفقات (Attachments) أو من

$$
\text { خلال إرسال روابط (links) معينه توصل إلى الهدف. }
$$

6. امكانية التحرير، الطباعة والتخزين (edit, print \& save) لجميع المواد المرسلة عبر البريد الإكتروني، وهذا

$$
\text { من شأنه زيادة الفائدة وأعاده إرسالها مره أخرى. }
$$

7. تعدد الإرسال، إذ يمكن إرسال الرسالة الواحدة نفسها في الوقت نفسه إدها إلى العديد من الجهات، اي مجموعة من

العناوين البريدية بنقرة واحدة (one click) وذلك باختيار ما نشاء من عنوانات من كتاب العنوانات

ومن ثم إدراجها في قائمه الجهة المراد الإرسال إليها. (address book)

8. معاينة الرسالة، عند كتابة رسالة على صفحة البريد الإكتروني هنالك امكانية تحرير وإخراج الرسالة بالثكل

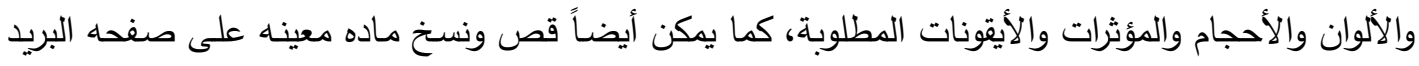

$$
\text { الالكتروني ومن ثم إرسالها على الهيئة (format) المناسبة. }
$$

9. امكانية الوصول في أي زمان ومكان، إذ يمكن للمشترك في خدمة البريد الالكتروني من فتح واستخدام بريده

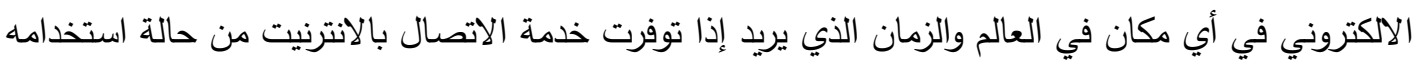

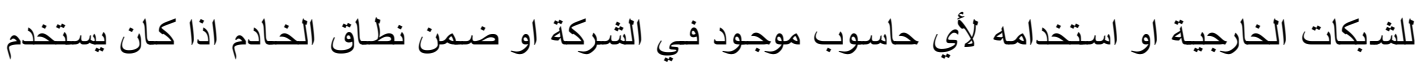
الشبكات الداخلية من دون التقيد بمكان معين.

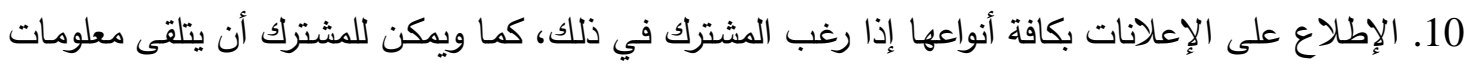

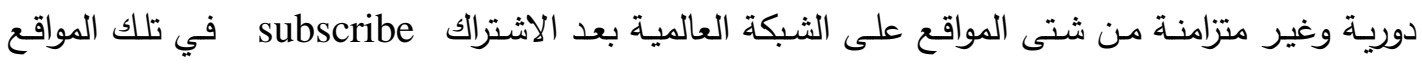
والمنتديات في حالة اشتراكه بخدمة البريد الاكتروني عن طريق الانترنيت او الحصول على اخر الاخبار

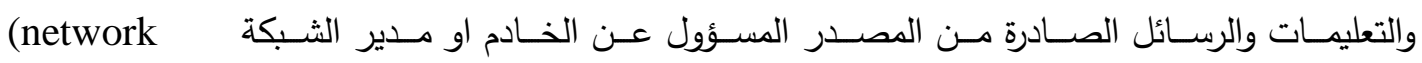
administrator)

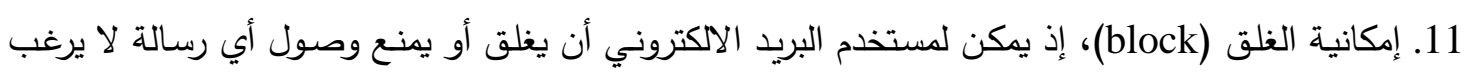
بها (spam) والتي تمثل رسائل مزعجة ومتطفلة تصل إلى البريد الالكتروني، والتي تمثل في معظم الأحيان إعلانات تجارية لمنتجات جديدة أو إعلانات لمواقع مختلفة أو ما شابه ذلك. تلك.

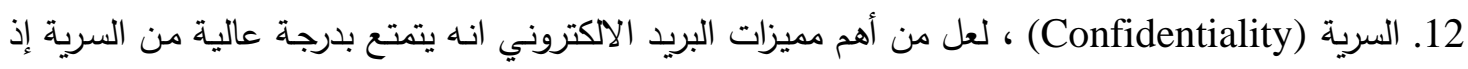

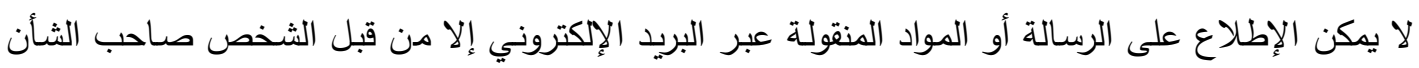
أي مستخدم البريد الإكتروني نفسه لأنه يدخل إلى بريده بواسطة اسم مستخدم وكلمة سرية.

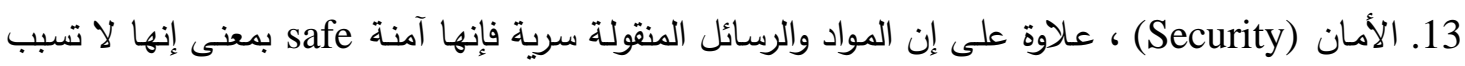
ضرراً جسمانياً مباشر كالمواد السامة أو الطرود المتفجرة على سبيل المثاد الرسال.

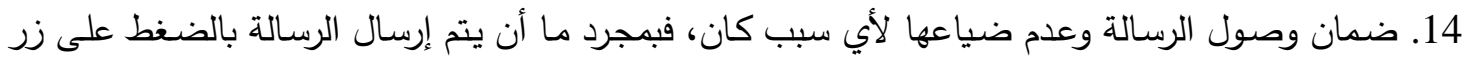

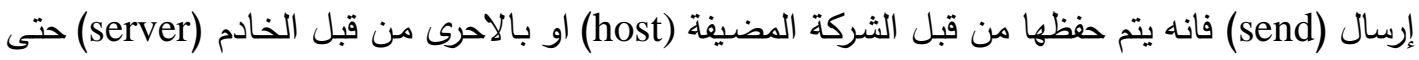
يتم تلقيها من قبل المرسل إليه (المستلم)، ولكن بشرط أن يكون قد وضـع عنوان البريد الصحيح ودون أي أخطاء. 15. تقوية العلاقات والروابط الاجتماعية سواء كان ذلك بين الزملاء ذوي الاختصاص أو المهنة أو على صعيد 


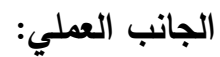

أولاً: وصف لثبكة الحواسيب الخاصة بالجامعة

تضم جامعة الموصل عدداً كبيراً من الكليات التي تحوي على اقسام مختلفة بحسب التخصص، وترتبط هذه الكليات بشبكة مشتركة عن طريق مجموعة مكونة من قابلات الالياف الضوئية Fiber optic cable التي تمتاز

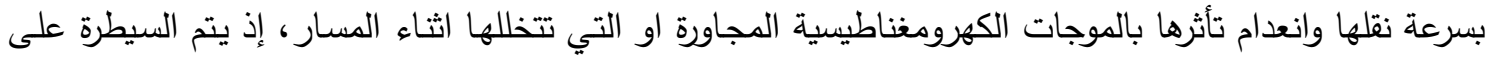
هذه الشبكة عن طريق المركز الرئيس في جامعة الموصل والمتمثل بمركز الحاسبة الاككترونية. إذ ان هذا المركز

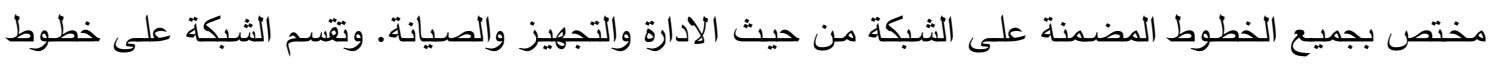

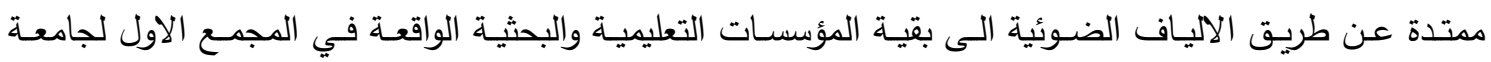
الموصل، تقسم هذه الكليات الى اقسام وفروع متعددة وقد تم تطبيق انموذج التراسل بكليات معينة وهي كليـة

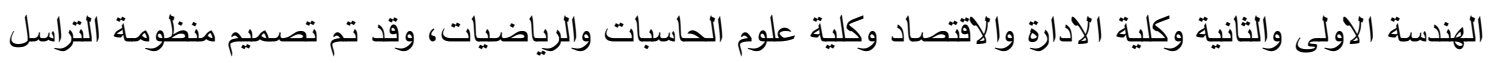

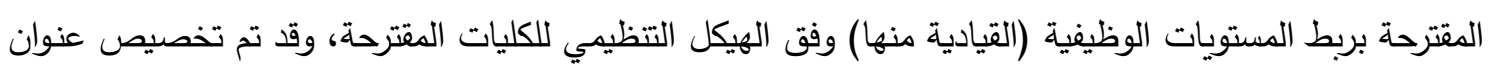

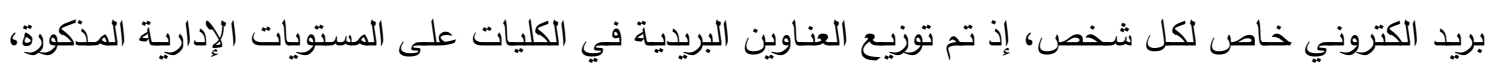
والمخطط التوضيحي الاتي يوضح المستويات المعنية في الأتصال داخل المنظومة المقترحة للتراسل.

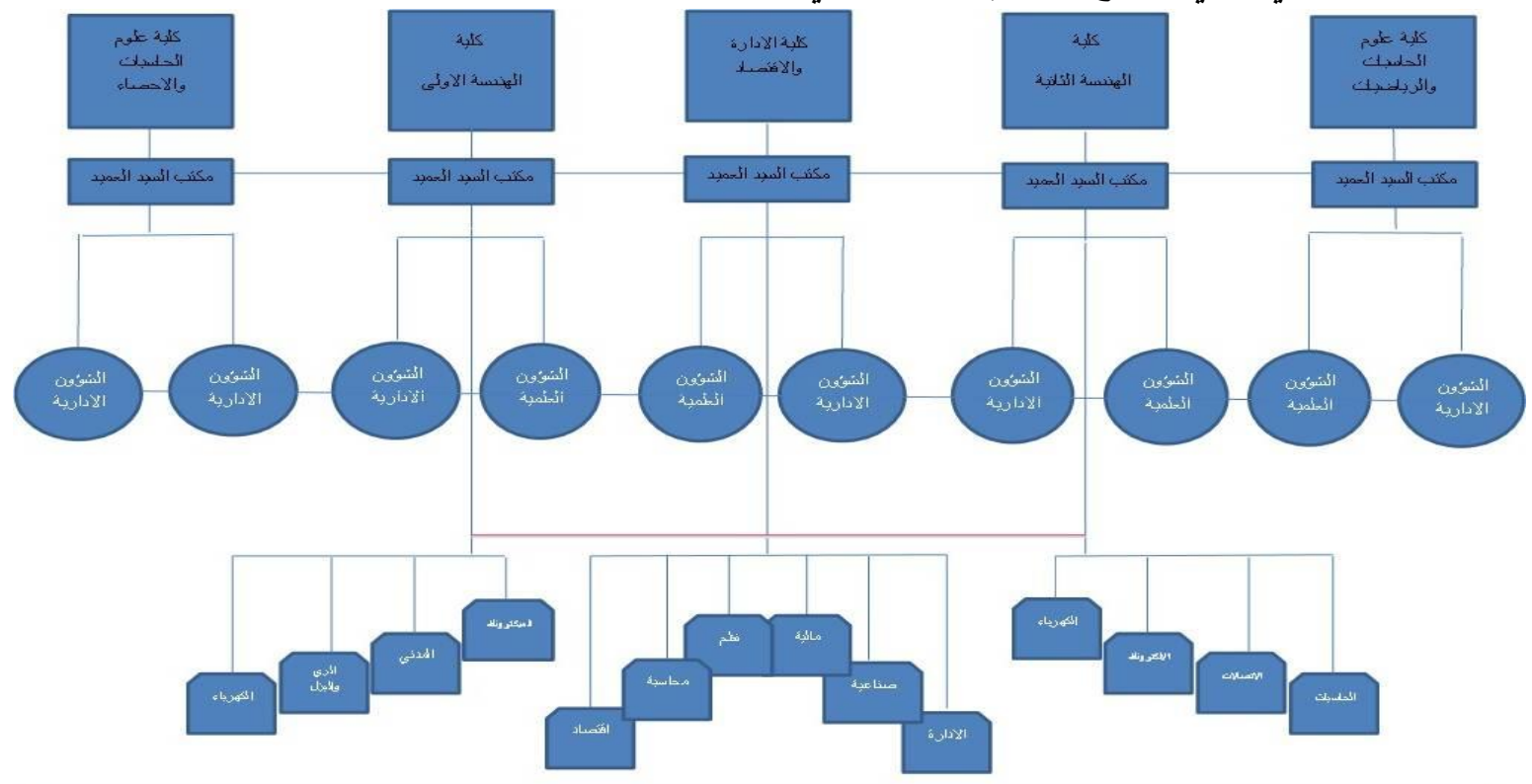

مركز الحاسبة الاككترونية

الثكل (1) يوضح الهيكل التظظيمي لتوزيع الشبكة المستخدمة في البحث

ثانياً: وصف الأنموذج المقترح للتراسل

تتقسم الشبكة في طبيعة الحال الى عدد من الاجهزة منها خاص لنقل الاشارة مثل نقاط الوصول والمفاتيح

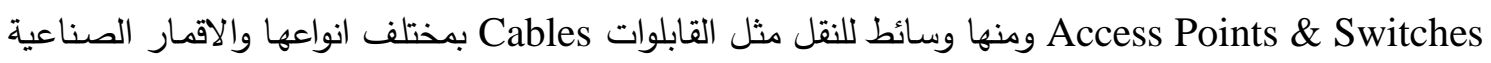
و اجهزة الموجات الدقيقة واجهزة اخرى مسـاعدة مثل المقسمات والمكررات Rultipliers \& Repeaters والخوادم Servers بمختلف انواعها واستخداماتها. 
وبهدف تطبيق الانموذج المقترح للتراسل عبر البريد الاككتروني الداخلي فقد تم أستخدام البنية التحتية لشبكة جامعة الموصل بوصفها شبكة داخلية من نوع (LAN)، والثكل (2) يوضح الانموذج المقترح لمنظومة التراسل

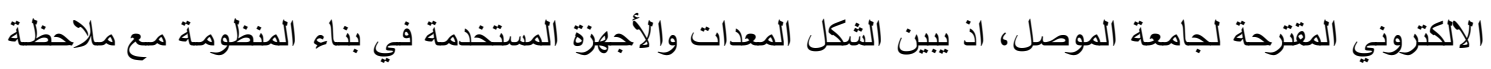

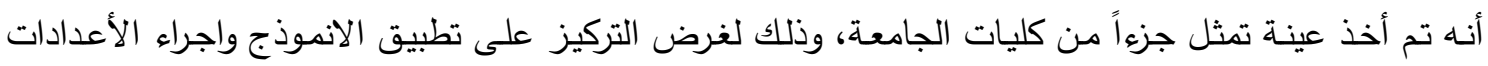

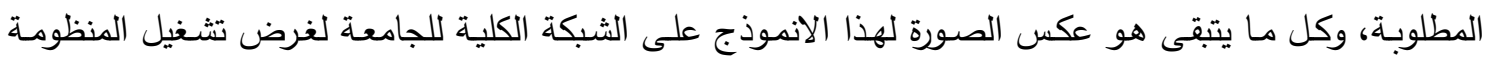
والاستفادة من خدماتها.

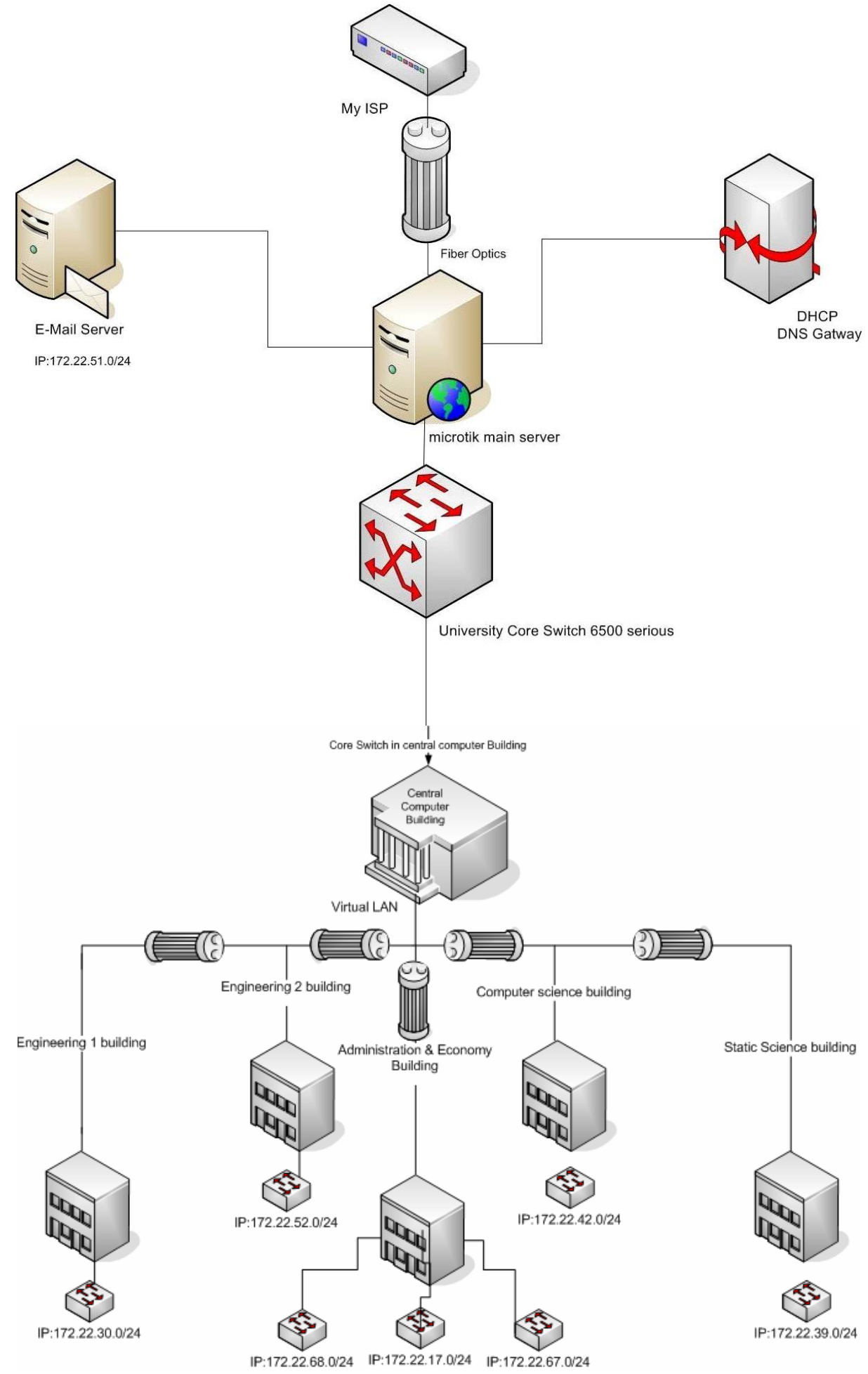

الثكل (2) هيكلية الثبكة للأنموذج المقترح في جامعة الموصل 
ثالثاً: الأدوات المستخدمة في بناء نموذج التراسل

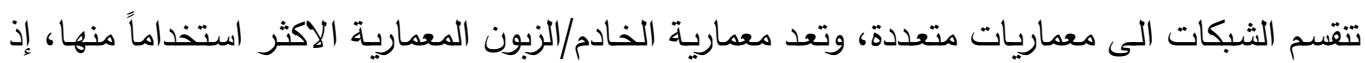

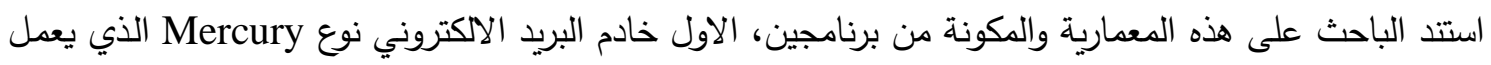

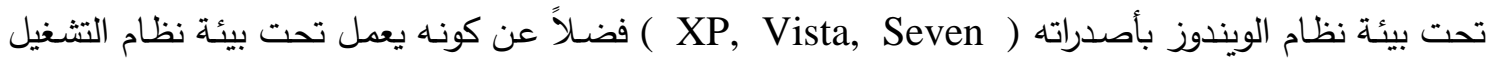

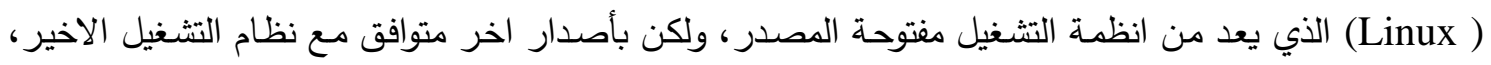

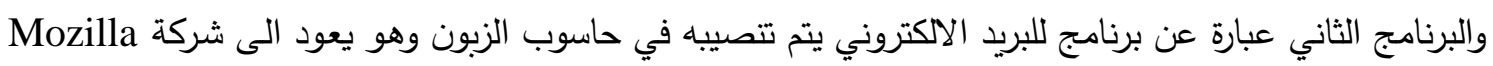

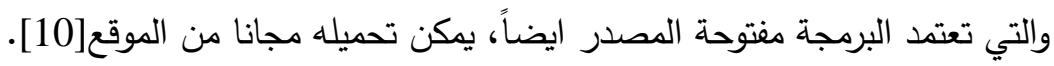

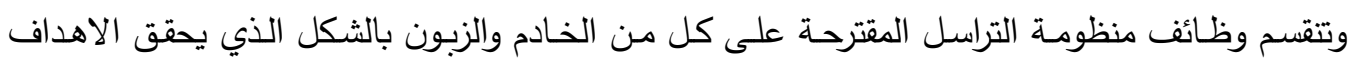
المتوخاة من هذه المنظومة، وسنقوم بشرح أهم العمليات الممكنة لكل من هذين البرنامجين والخصائص والادوات التي يتميز بها في الفقرات أدناه.

\section{1 برنامج الخادم Mercury Server}

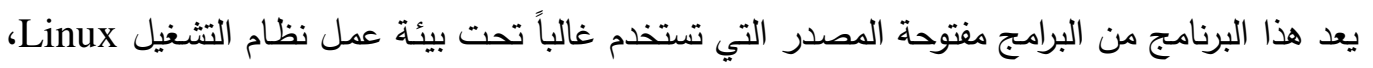

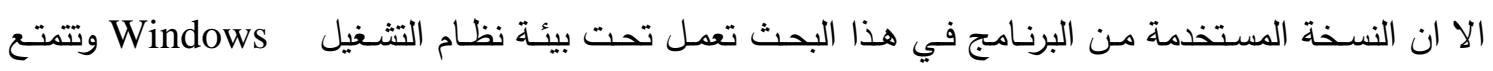

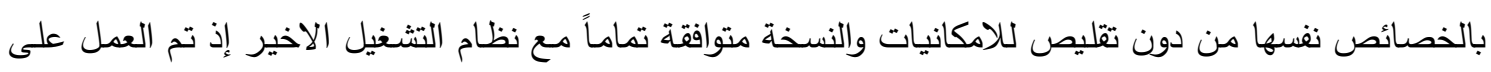
ضبط الاعدادات وانثاء حاسوب خادم خاص به وتم انثاء حسابات متعددة وفحصها وتثغيلها، وهو متوافق ايضاً

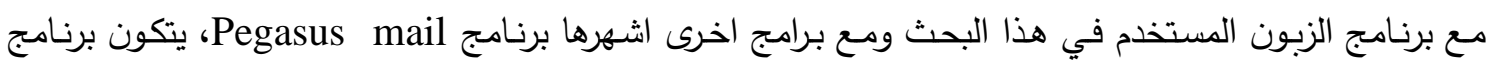

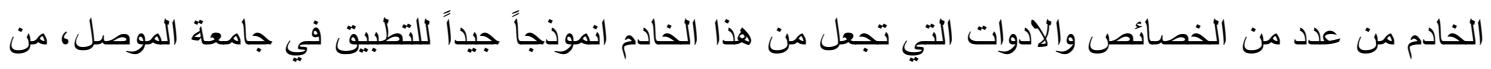
اهم مكونات هذا البرنامج :

\section{Main Window ألو الوجة الرئيسة}

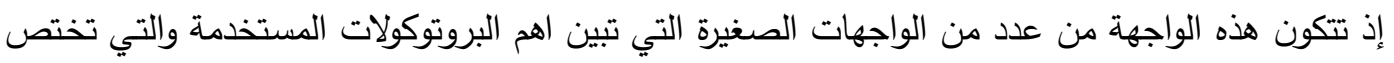

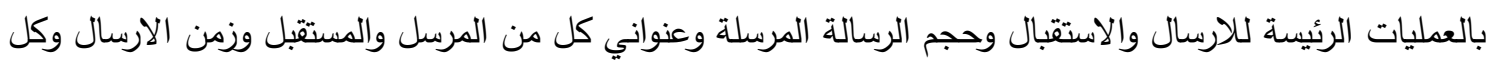

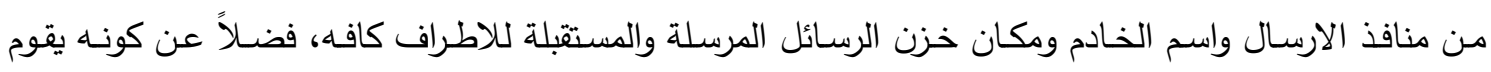
بأظهار عدد عمليات الارسال من وقت دخول الخادم للعمل، والثكل (3) يوضح الواجهة الرئيسة للبرنامج.

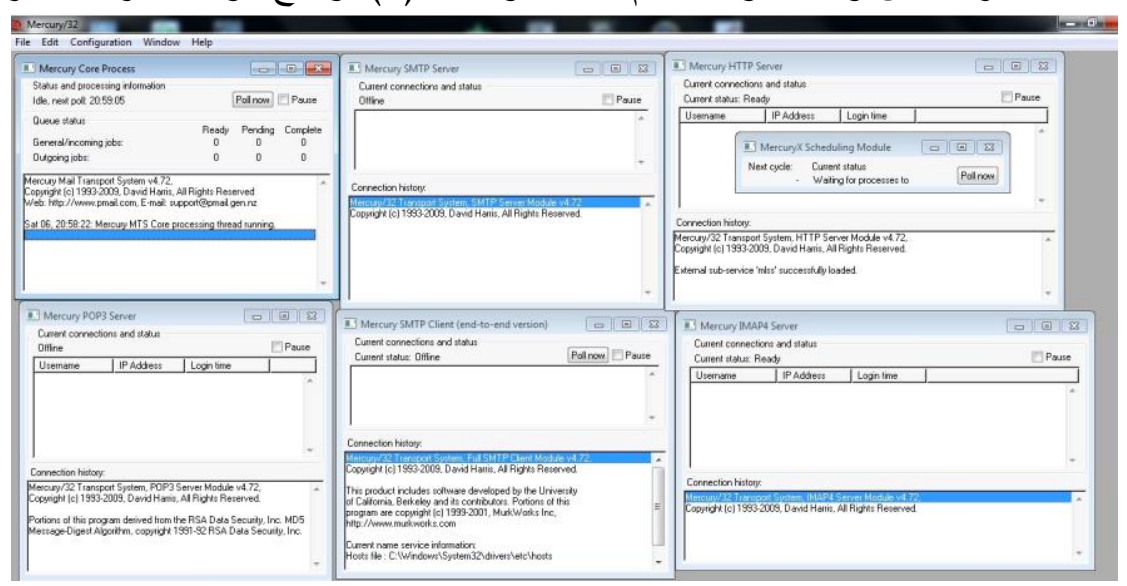

الثكل (3) الواجهة الرئيسة لبرنامج الخادم 
أما عن الوظائف التي تتفذ من خلال النوافذ المكونة للواجهة الرئيسة للبرنامج فيمكن وصفها بالأتي :

\section{Core process • •}

تبين هذه النافذة لمدير الخادم اهم العمليات التي تتم على سير الارسال إذ تعطي حالة الخادم Idle والتي

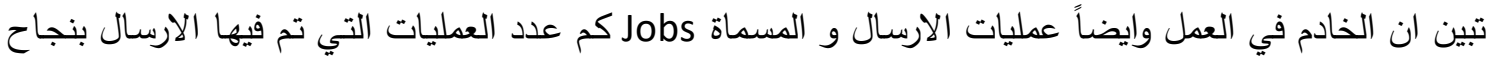

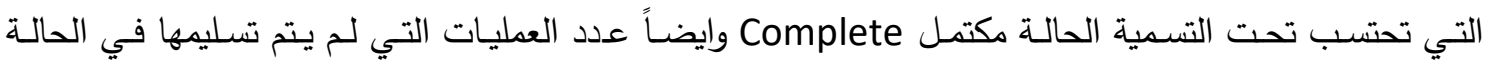
Pending والعمليات التي تم استلامها من قبل الخادم ولم يتم تسليمها الى المرسل اليه تحت الحالة Ready، كما

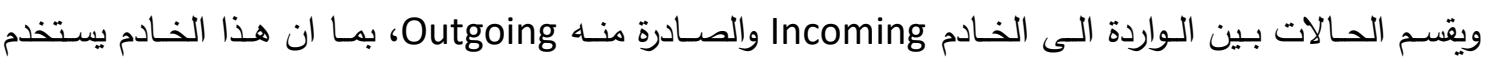
البروتوكولات الخاصـة بسحب البريد الالكتروني فأن هذه الواجهة تحتوي على الزمن القادم لعملية سحب البريد

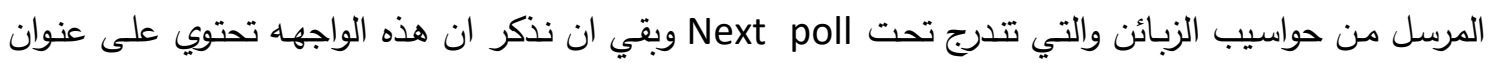
المرسل والمستقبل ووقت ارسال الرسالة وتاريخها كما مبين في الثكل(4) ادناه.
[1.' Mercury Core Process
Status and processing information
Idle, next poll: 21:44:46
Queue status
General/incoming jobs:
Outgoing jobs:
Mercury Mail Transport System $\vee 4.72$,
Copyright (c) 1993-2009. David Harris, All Rights Reserved
Web: http://www.pmail.com, E-mail: support@pmail.gen.nz
Sat 06, 21:26:48: Mercury MTS Core processing thread running.
Sat 06, 21:27:10: Job MG000001: from mab@localhost (local)
To: mustafa (local) - $0 \mathrm{~K}$
Sat 06, 21:43:30: Job MG000002: from mab@localhost (local)
To: mustafa (local) - DK
Sat 06, 21:43:52: Job MG000003: from mustafa(@localhost (local)

$\square \quad \square \quad x$

Poll now $\square$ Pause

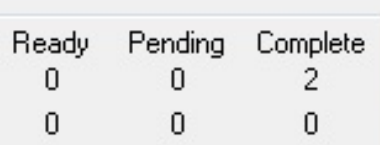

To: mab llocall-OK

Core Process الثكل (4) نافذ العمليات الاساسية

SMTP Server نافذة بروتوكول

تستخدم هذه النافذة لاظهار الاتصالات التي تحدث اثثاء عمليات الارسال والاستقبال إذ عند ارسال الرسالة

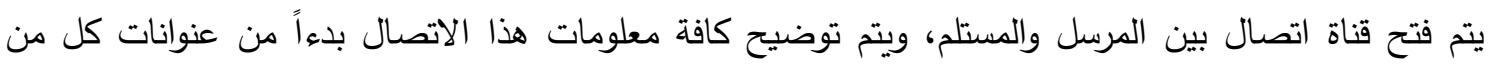

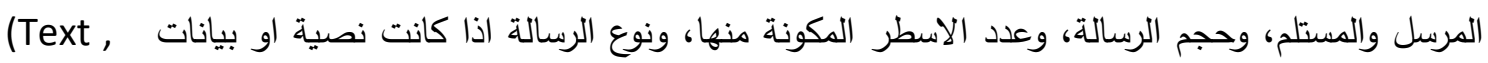

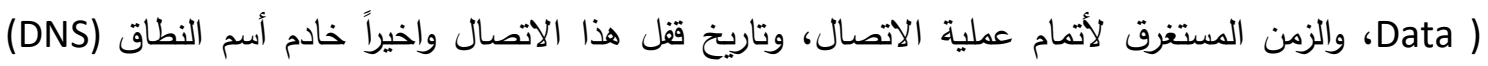
المستخدم اثناء عملية الاتصال وهو Local host وكما مبين في الثكل(5) ادناه. 


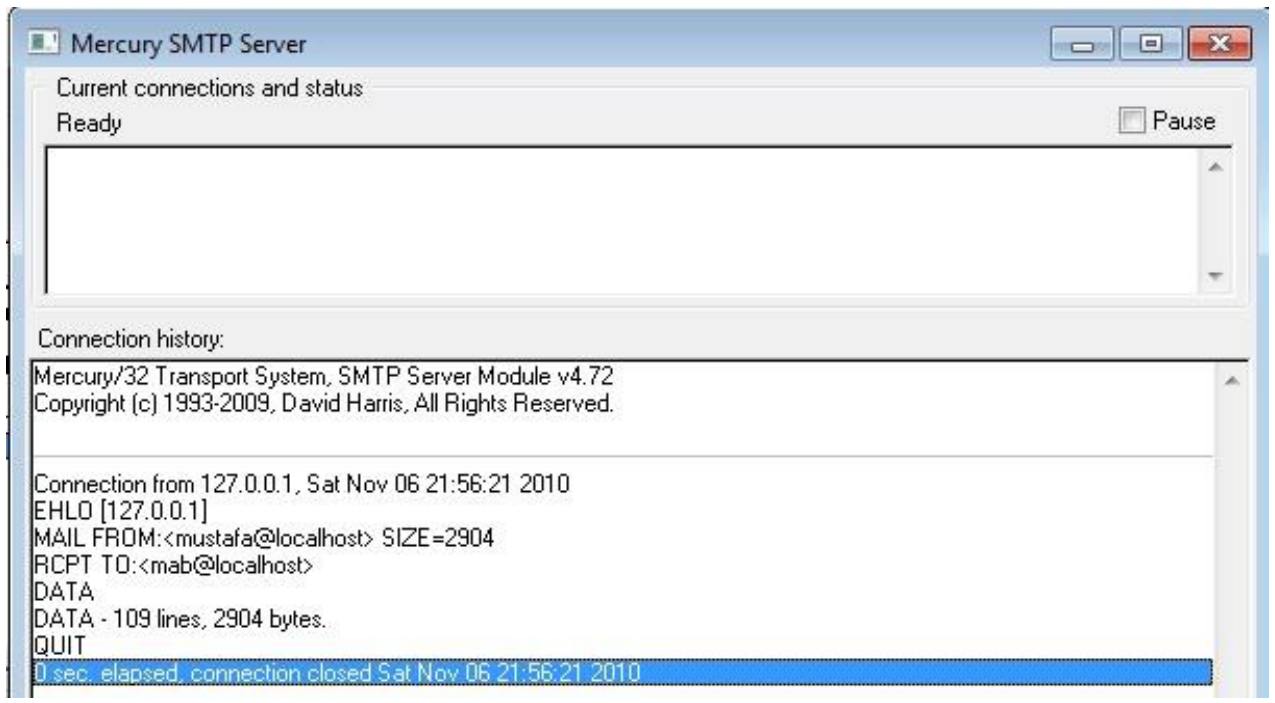

SMTP Server الثكل (5) نافذة بروتوكول

نافذة بروتوكول POP3 Server

عند ارسال الرسالة من المرسل تمر عبر الخادم الذي يقوم بتمرير الرسالة بعد استلامها الى المستقبل، إذ يعد بروتوكول POP3 بروتوكولاً لاستلام الرسائل او جلب الرسائل من الخادم الى الزبون، وبعبارة أخرى فأنه يعد

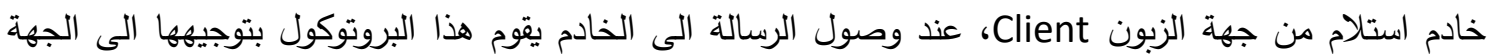

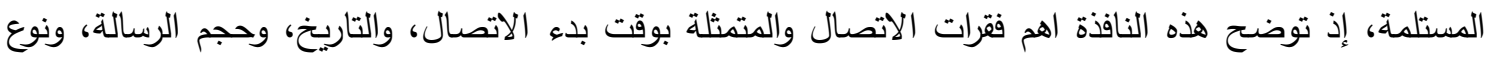
الرسالة (Text, Data)، وتاريخ انتهاء جلسة الاتصال، والوقت المستغرق لهذه الجلسة، واسم المستخدم للمستلم، وعدد الرسائل المستلمة، كما انها تبين اسم المستخدم وكلمة المرور وزمن الجلسة المستغرق اذا كان الخادم يعمل

عن طريق المتصفح Web Based Mail الذي يعمل مع برتوكول HTTP Server وكما مبين في الثكل (6).

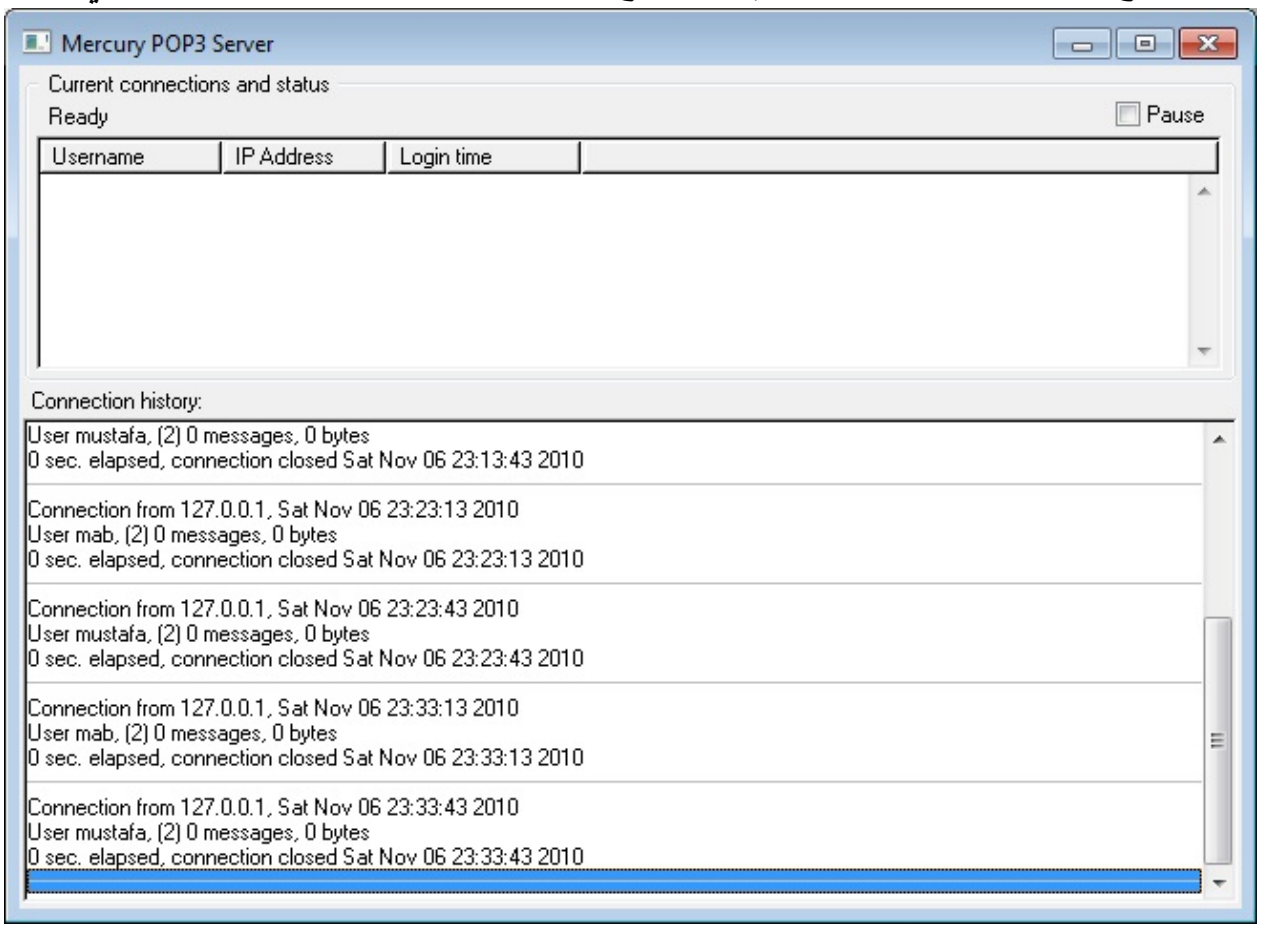

POP3 الثكل P(6) نافذة برتوكول 
• نافذة بروتوكول IMAP و HTTP

تستخدم نافذة بروتوكول IMAP Server في حالة الغاء العمل ببروتوكول POP3 وذلك لان لهذا البروتوكول

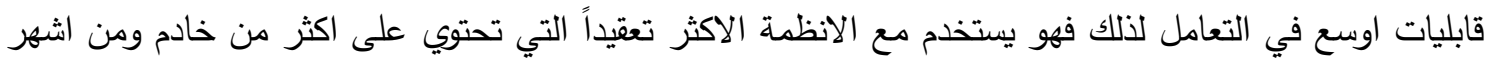

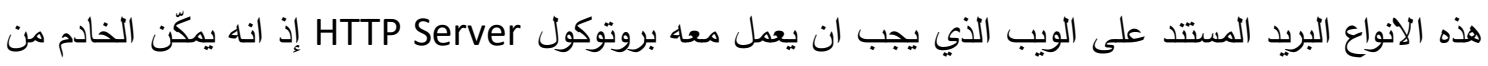
العمل عن طريق متصفح الانترنت Web Browser مع واجهات مشابهة لتلك المستخدمة في متصفحات الانترنيت ومنها (Yahoo Mail, Hot Mail, Gmail). وسنكتفي بهذا القدر من وصف هذه النافذة إذ انها لم تستخدم في منظومة التراسل المقترحة في هذا البحث.

ب. قوائم الخيارات Select Menus

تعد قوائم الخيارات من الادوات المهمة في جميع البرامج، وتسمى ايضاً بالقوائم المنسدلة، تحوي هذه القوائم

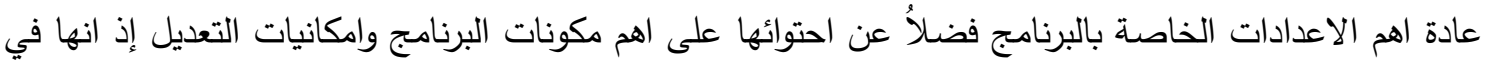
برنامج الخادم تضم عدد من الادوات المهمة نذكر منها: Send a Mail Message ق • • لفتح هذه القائمة يتم اختيار Send a mail Message من قائمة File تمكّن هذه القائمة مدير الخادم Server Administrator الخادم بكتابة عناوين البريد الاكتروني للاشخاص الذين يرغب بأرسال الرسالة اليهم ومن ثمة كتابة الرسالة في الدي خانة النص ثم يحدد حالة الرسالة اذا كانت مستعجلة Urgent إذ يتم تأشير المربع الخاص بذلك، وتمكننا ايضاً من استلام رسالة تأكيد الاستلام Confirm Delivery من قبل المستلم، وايضاً تأكيد بالقراءة من قبل العناوين

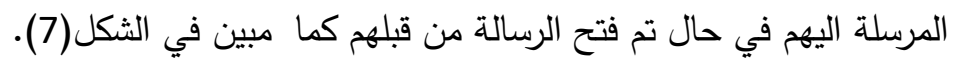

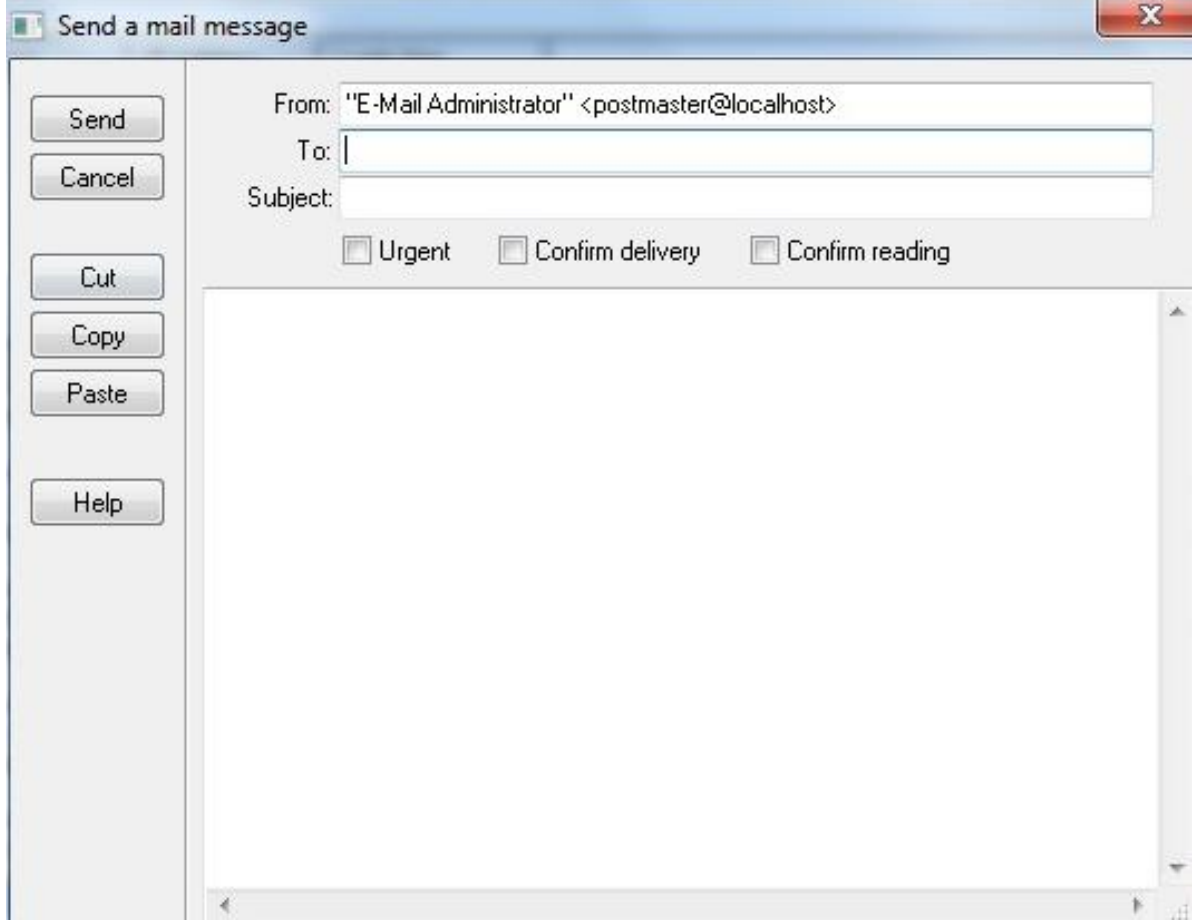

Send a Mail Message الثكل (7) قائمة الارسال 


\section{Configuration قائمة الضبط}

تحتوي هذه القائمة على العديد من خيارات الضبط فضلاً عن خيارات تحديد الخصائص المهمة في عمل

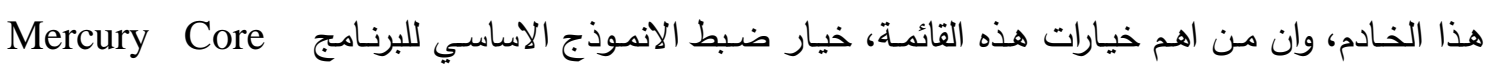
Module Configuration

$$
\text { تضم عدداً من الفقرات (Tabs) التي يمكن عن طريقها : }
$$

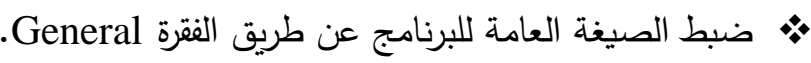

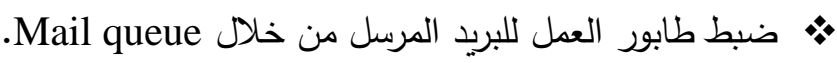

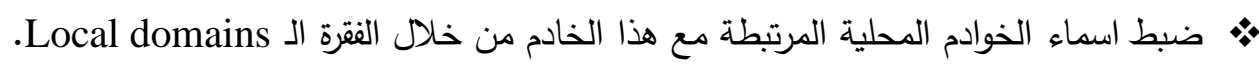

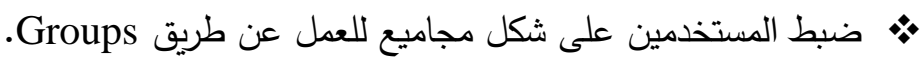

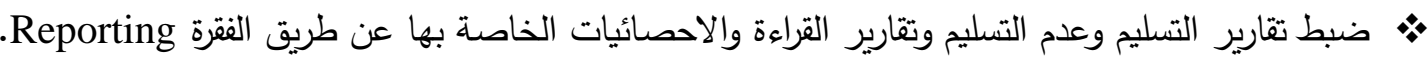

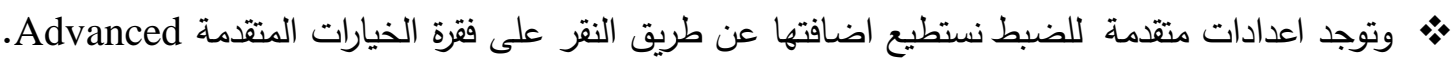

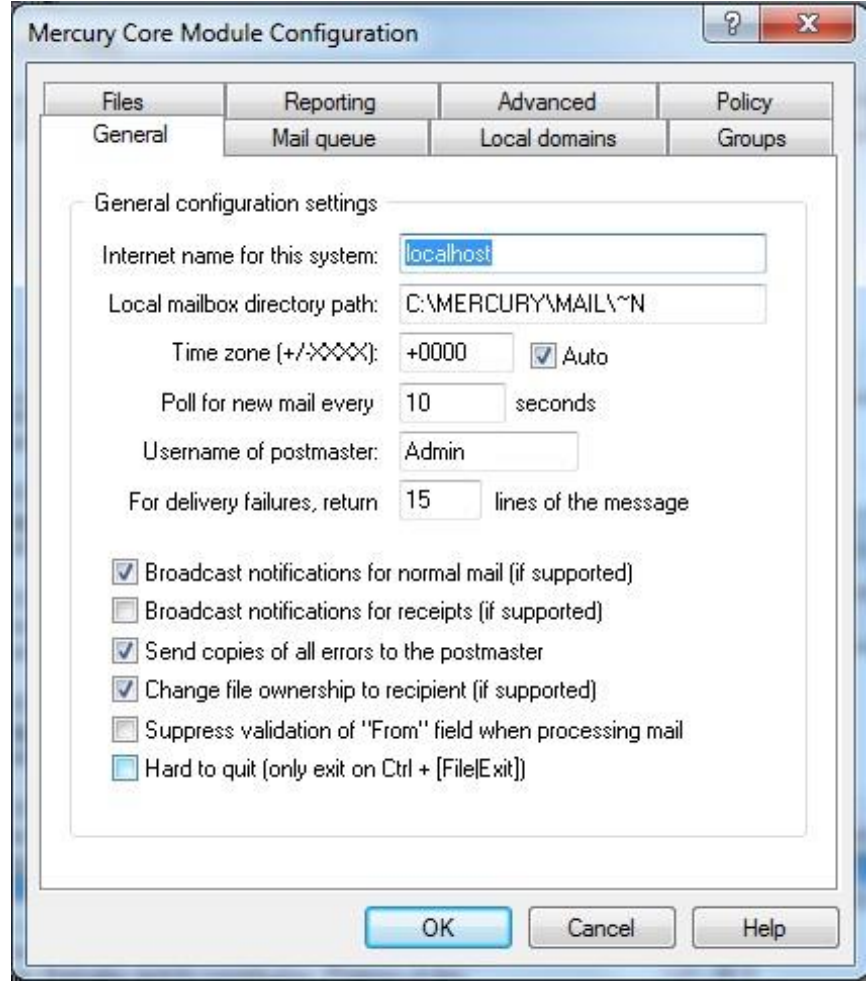

Core module configuration الثكل(8) قائمة الضبط الاساسية

Protocol Modules قائمة البروتوكولات

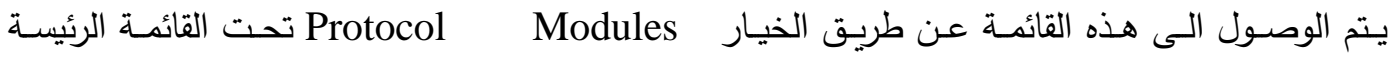
هonfiguration هذه البروتوكولات عن طريق تأثير مربع الخيار المجاور لله، إذ عند التاشير وبعد اعادة تشغيل البرنامج ستظهر نوافذ البروتوكولات التي تم تأثيرها سابقاً في الواجهة الرئيسة للبرنامج والثكل (9) يوضير لئح محتويات هذة القائمة. 


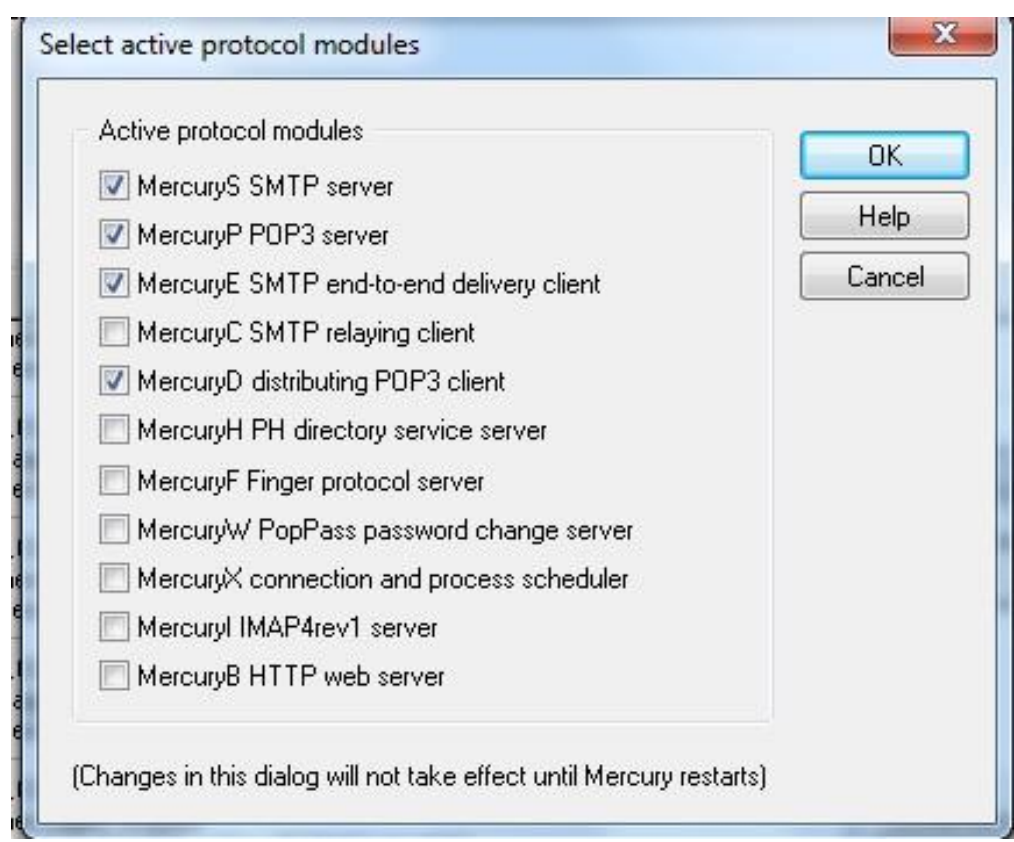

Protocol Modules الثكل (9) قائمة البروتوكولات

\section{Manage Local Users}

يتم عن طريق هذه القائمة اضافة، حذف، أو تعديل في حسابات المستخدمين على الخادم، فمثلاً يتم اضافة اسم المستخدم (عنوان البريد الاككتروني) على الخادم عن طريق النقر على زر الخيار Add، وكما يوضح في الثكل (10)، ومن ثمة ستظهر نافذة اخرى (الموضحة في الثكل (11)) والتي تم من خلالها ادخال معلومات المستخدم الجديد (User Name)، والاسم الشخصي لمستخدم هذا البريد (Personal Name).

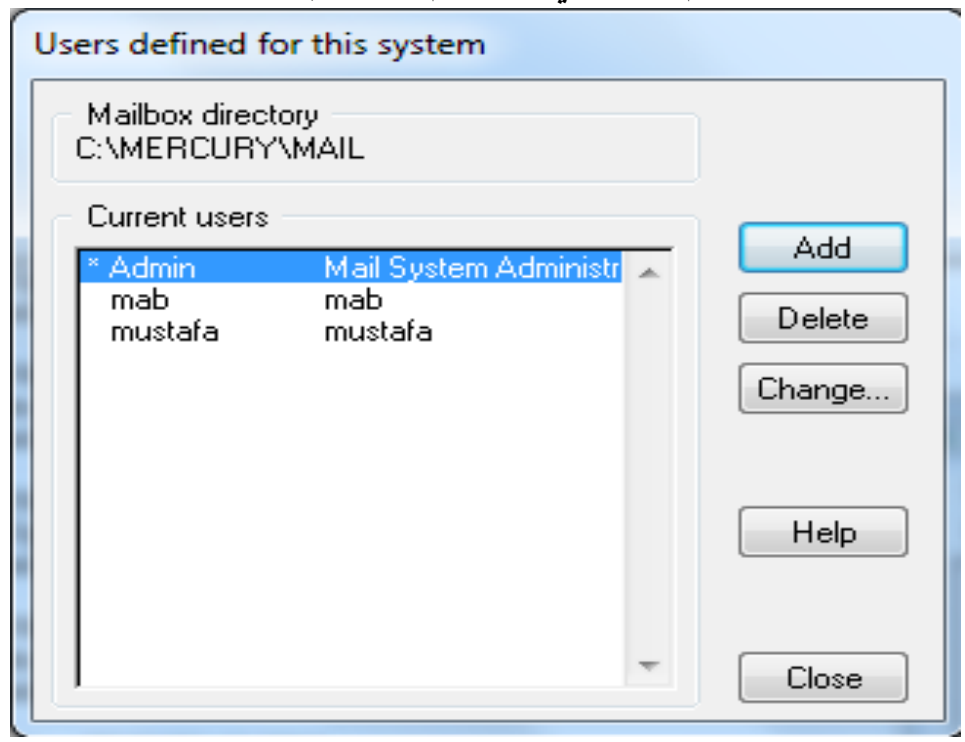

Manage local users الثكل (10) نافذة أدارة المستخدمين

كذلك تحتوي نافذة الأضـافة على حقل خاص لأدخال كلمـة السر والتي تعد مهمة جداً في جلب البريد

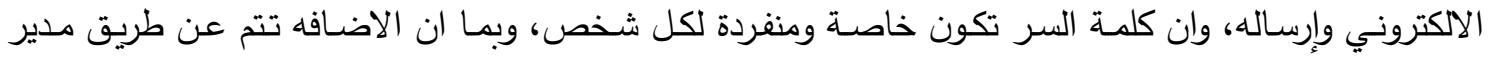

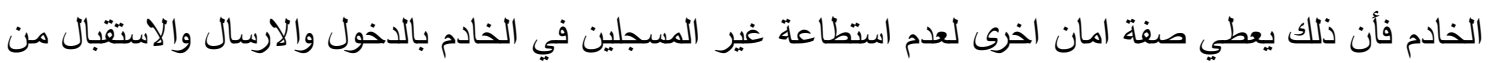




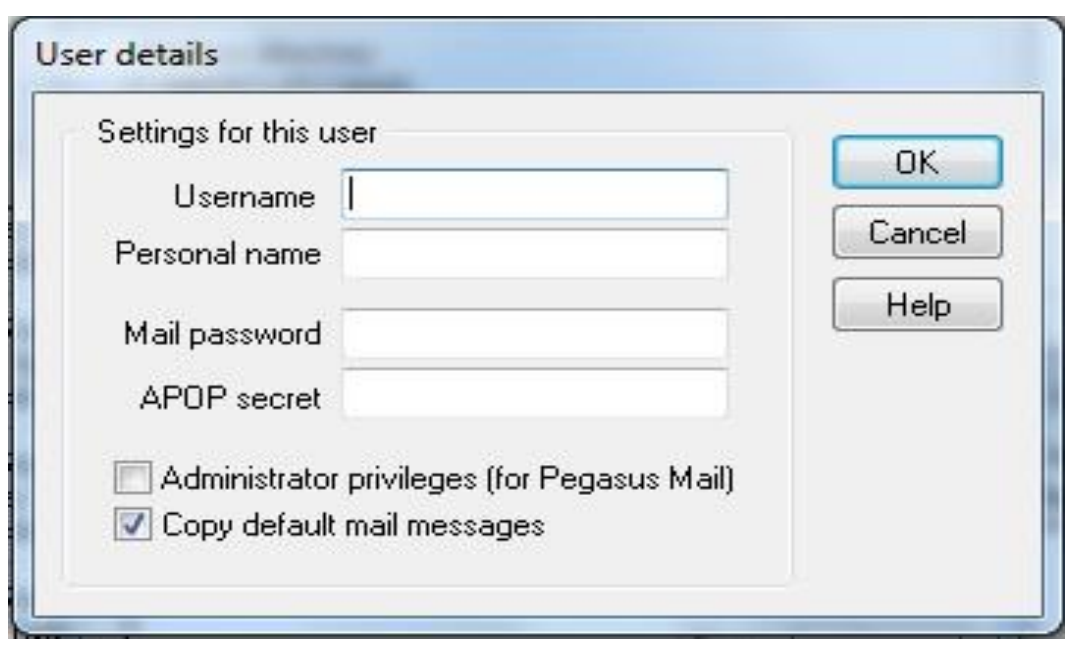

الثكل (11) نافذة اضافة معلومات المستخدم الجديد

كما ويتمتع برنامج الخادم المستخدم في منظومة التراسل بالعديد من المزايا الاخرى التي لم يتم ذكرها ومن

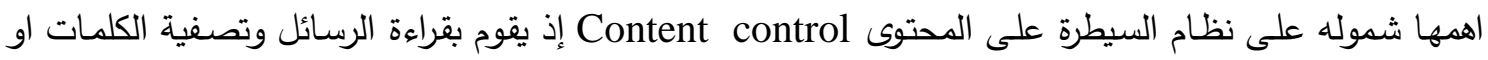

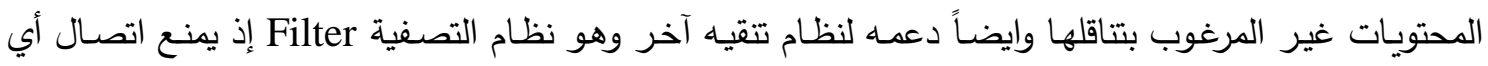

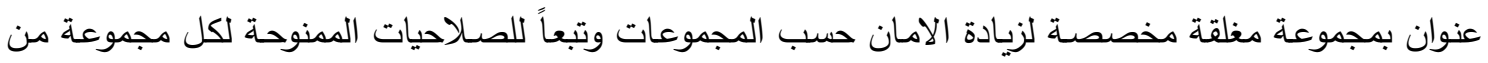
المجاميع عن طريق مدير الخادم Server administrator.

\section{Client Program: Mozilla Thunderbird برنامج الزبون}

يعد برنامج Thunderbird من البرامج حديثة النشأة، وسريعة التطور ، إذ استطاعت هذه المجموعة من

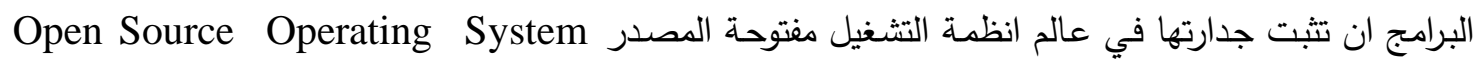
وبسبب الانتشار الواسع لها فقد نظمت إصدارات اخرى تعمل في بيئة نظام التشغيل Windows، مع بقاء هذه

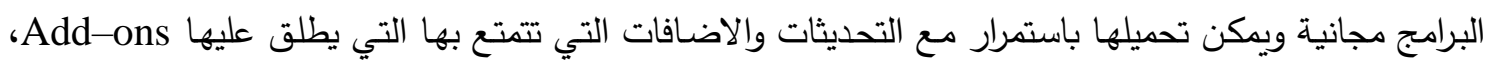

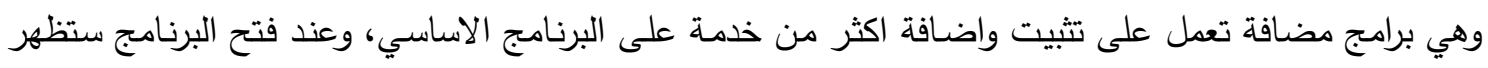

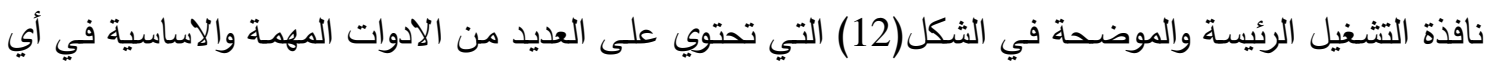
برنامج للبريد الالكتروني، مع عدد من الادوات الاخرى التي تفتقر اليها معظم تلك البرامج، ومن اهم هذه الادوات :

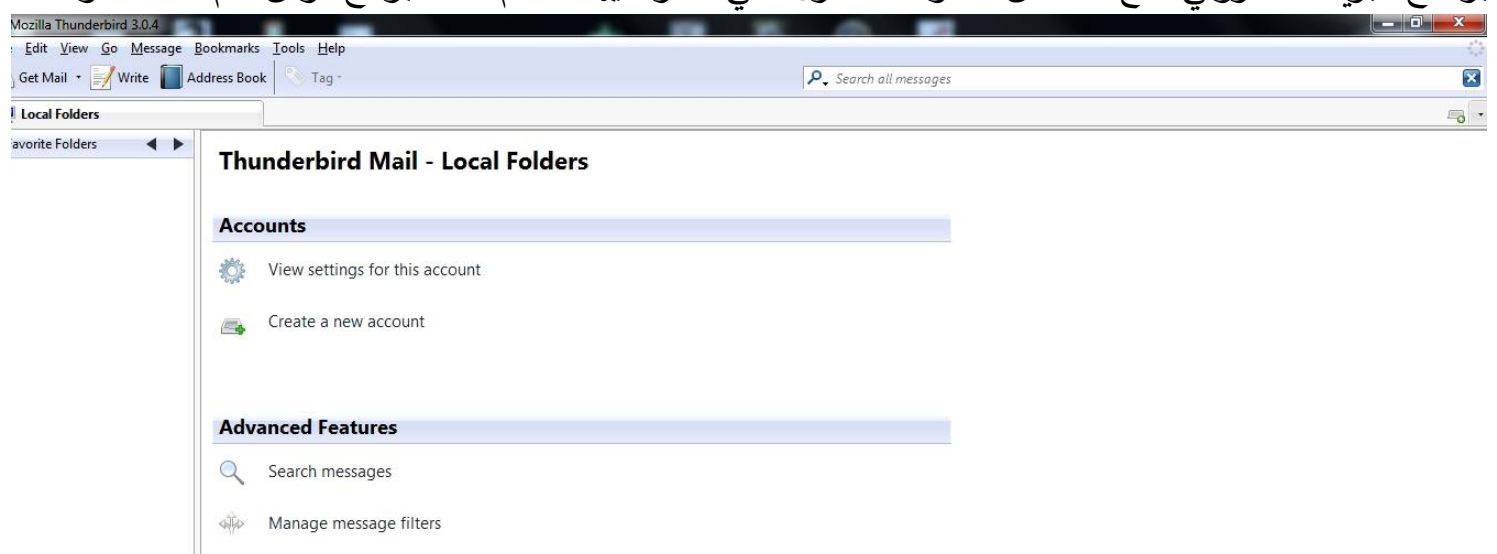

Mozilla Thunderbird الثكل (12) الواجهة الرئيسة لبرنامج 
Create a new account أنثاء حساب جديد

ويتم من خلال هذا الرابط تكوين حساب جديد للبريد الالكتروني، فعند النقر على الرابط ستظهر نافذة تحتوي على مجموعة من الحقول والتي تتضمن حقل اسم المستخدم User name الجديد وهو اسم تعريف لصاحب البريد الالكتروني، وبعدها يتم ادخال البريد الالكتروني الجديد ويكون من مقطعين : • الاول يتمثل بعنوان البريد الالكتروني الجديد الذي تم اضافته سابقاً في برنامج الخادم ويجب اندئ ان يكون مطابقاً

• والثاني يتمثل بأسم النطاق للخادم Domain name إذ تم استخدام اسم النطاق الخاص في الثبكات الداخلية وهو المضيف المحلي Local Host ولايحتاج اسم النطاق هذا للاتصال بالانترنيت إذ يكتفي بأعدادات الخادم

$$
\text { للشبكات المحلية (LAN). }
$$

يفصل بين اسم عنوان البريد الاككتروني واسم النطاق الرمز @ للدلالـة على عنوان البريــ الالكتروني

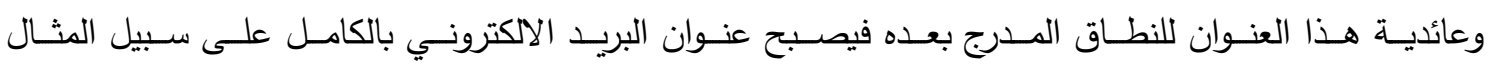
Mustafa@localhost

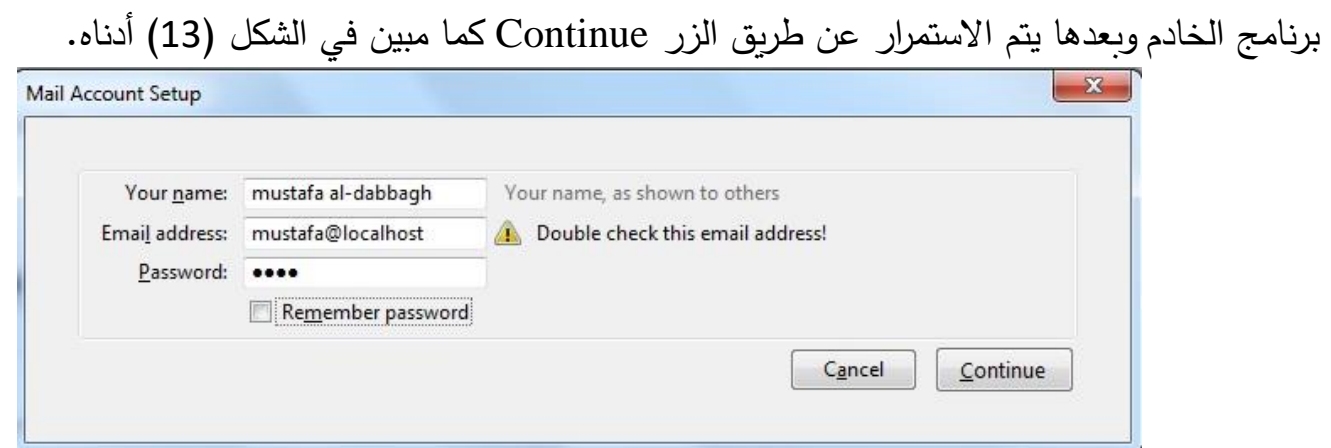

Mail Account Setup 1 الثكل (13) اعدادات انشاء حساب جديد

عند الانتهاء من كتابة المعلومات السابقة والاستمرار عن طريق الزر Continue ستظهر نافذة ثانية تبين البروتوكولات المستخدمة في انثاء الحساب إذ ان هذه البرتوكولات تعمل عن طريق منافذ محددة، بمعنى اخر ان لكل بروتوكول على الثبكة رقم منفذ خاص به، وسيقوم البرنامج تلقائياً بالبحث عن المنافذ المستخدمة وهل ان هذا

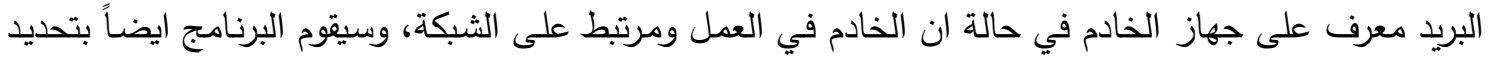
اسم النطاق للخادم للرسائل الواردة والمسمى بـ Incoming واسم النطاق للرسائل الصـادرة Outgoing وبعدها يتت الضغط على الزر Create account لأتمام عملية تسجيل الحساب البريدي الجديد كما في الثكل (14) ادناه.

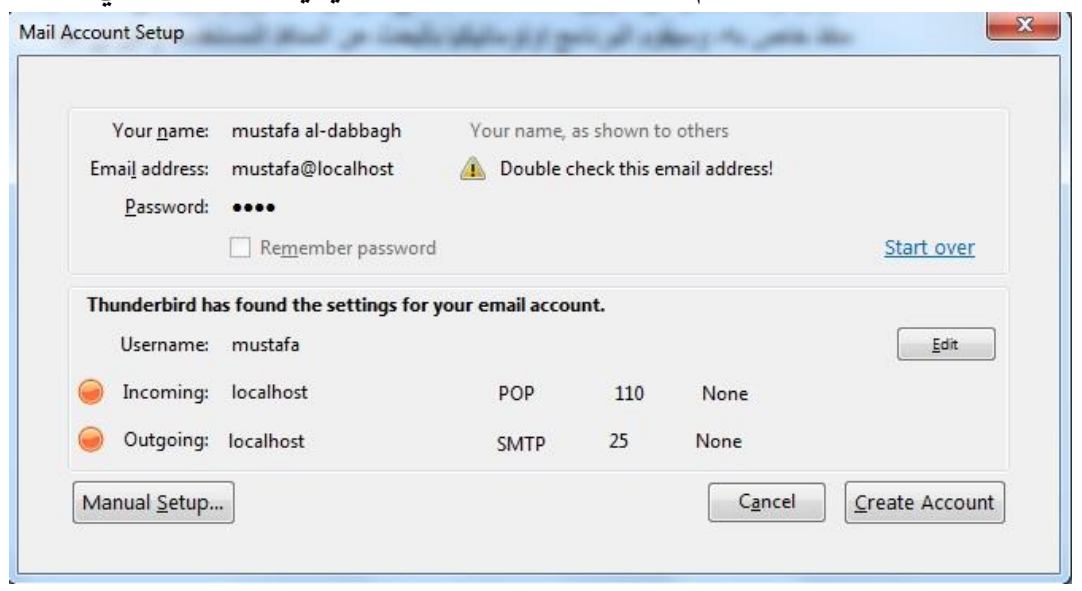

Mail Account Setup 2 الثكل (14) النافذة الثانية لإعدادات إنشاء البريد الإكتروني 


\section{Account Settings ب. إعداد ضبط الحساب}

View بعد استكمال عملية انشـاء الحسـاب الجديد يتم ضـبط اعدادات الحسـاب الداخلية عن طريق settings for this account الخصـائص التي تبدأ بعنوان البريد الاككتروني وتتنهي بخانة الـ Security ( انظر الثكل (15) ) التي يمكن تلخيصها بالاتي: • خانة البريد الآكتروني : عند تأثير هذه الخانة ستظهر مجموعة من الخيارات متمثلة بالاعدادات الاولية

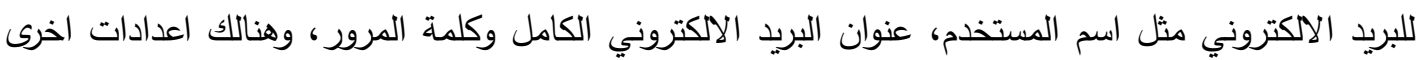

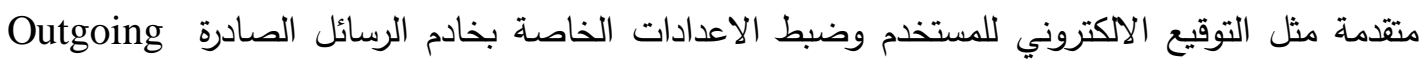
.server • خ خانة اعدادات الخادم الرئيس Server settings إذ تمكّن هذه الاعدادات المستخدم من التعديل او الاضـافة

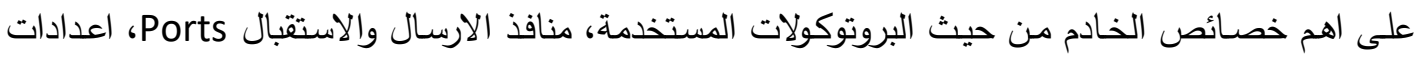
الامان الخاصه بالاتصال، واعدادات تخص مدة بقاء الرسائل في صندوق الوارد ... الخ، فضلاً عن احتوائها

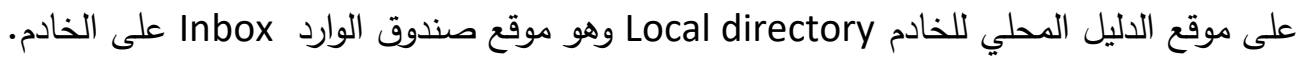
• • خانة الملفات والنسخ الاحتياطي Copies \& Folders التي تحتوي على مواقع خزن الرسائل المرسلة سابقاً

Sent، مواقع الرسائل المحفوظة Archive او قوالب الرسائل الجاهزة Templates والمسودات Drafts. • التكوين والعنونة Composition \& addressing وتضم صيغة انثاء رسالة البريد الالكتروني، مواقع حفظ عناوين البريد الالكتروني للمستخدمين الاخرين على الشبكة والخادم الخاص بعملية العنونة.

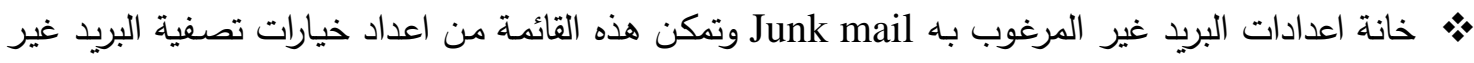
المرغوب به التي تحدد من قبل المستخدم لعنوانات معينة يرغب بعدم استلام الرسائل منها، فضـلاً عن تحديد

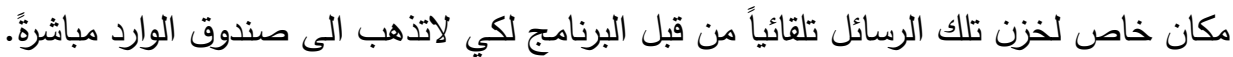
•• مساحة الخزن على القرص الصلب Disk Space يقوم المستخدم عن طريق هذه الخانة بالاعدادت الخاصـة بالسماح بتخزين الرسائل ذات حجم معين فقط بينما تبقى الرسائل الاخرى باستضافة الخادم.

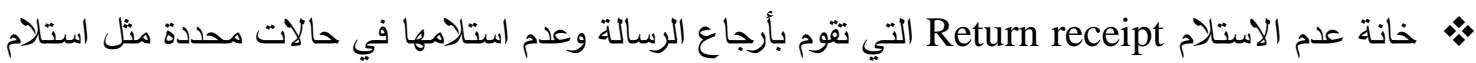
رسالة من نطاق اخر او عندما يكون المرسل غير معروف في قائمـة العناوين البريدية الخاصـة بالمستخدم (الخ....

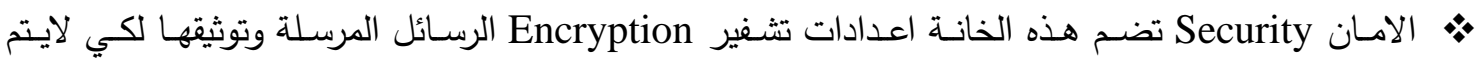
اختراقها من قبل غير المصرح لهم اثثاء انتقالها عبر وسائل الاتصالات المختلفة في الثبكة. 


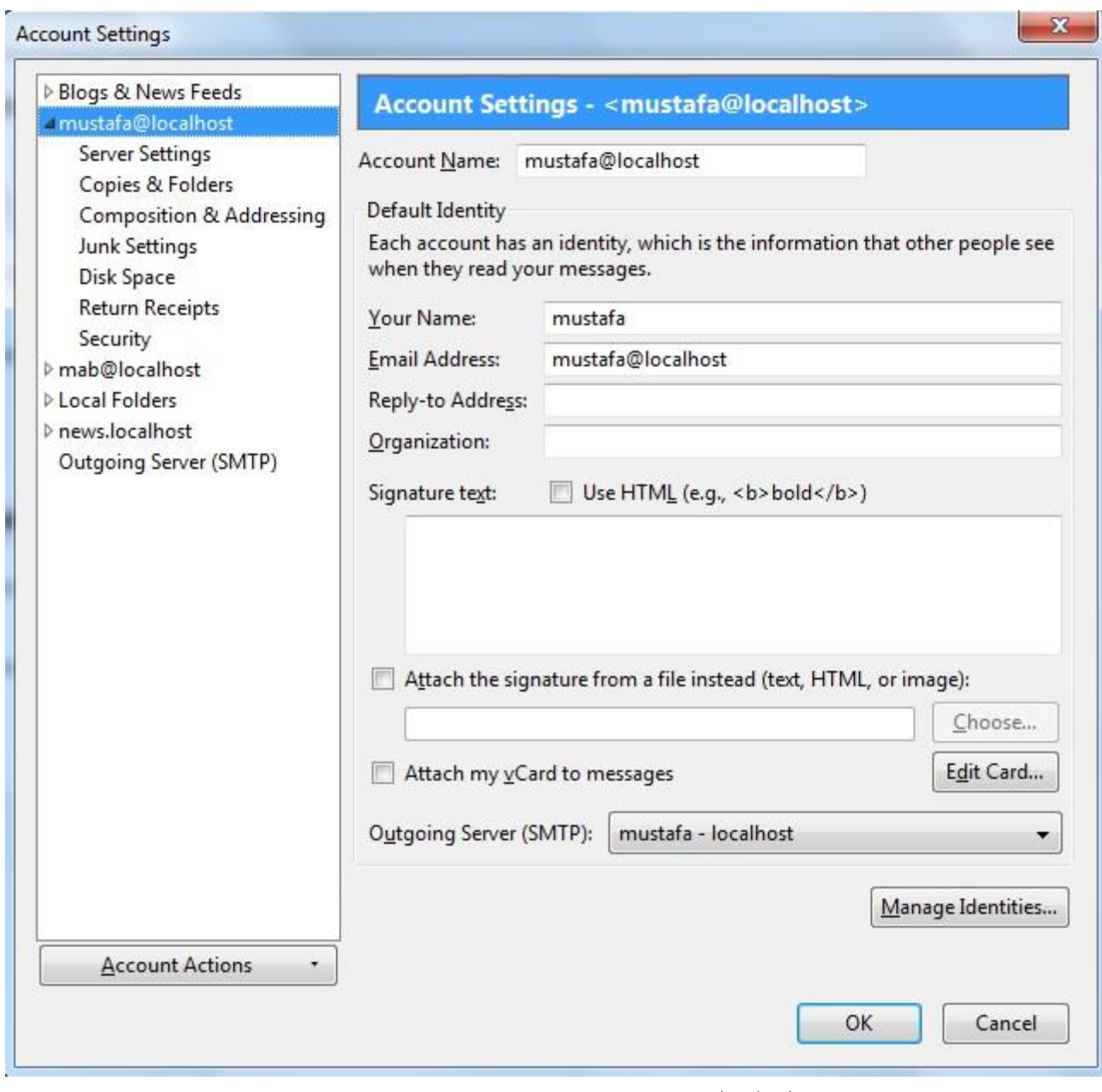

$$
\text { الثكل (15) نافذة الإعدادات الخاصة بالبريد الالكتروني }
$$

رابعاً: الاستنتاجـات وإلتوصيات

أ. الاستنتاجات

$$
\text { خلصت الدراسة الى مجموعة من الاستنتاجات يمكن ايضاحها بالثكل الاتي: }
$$

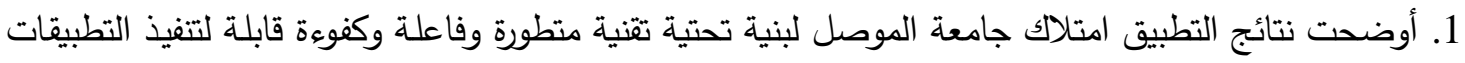
الحديثة عليها واستيعابها للعديد من التطبيقات المختلفة لذا تعد مناسبة لتطبيق انموذج التراسل الاككتروني

$$
\text { المقترح. }
$$

2. اوضـحت نتائج تطبيق أنموذج التراسل الالكترونـي المقترح امكانيـة زيـادة درجـة الامـان والسرية عن طريق التراسل الالكتروني المؤمن على الثبكة الداخلية (الانترانيت) لجامعة الموصل وذلك بأستخدام احدث استاليب التشفير في برنامجي Mozilla Thunderbird و Mercury Server المتاحة على الطبقات مثل ( TLS

3. تبني استخدام التطبيقات مفتوحة المصدر Open Source توفر العديد من المزايا لمستخدميها فضـلاً عن

$$
\text { احتوائها على ميزات اضافية تفتقر اليها البرامج الاخرى. }
$$

4. امكانية توفير النظام المقترح لخدمة البريد الاكتروني فضلاً عن تراسل البيانات بأحجام كبيرة ولعدد كبير من التهات الصيخ من امثلتها (doc, exe , rar, jpg, mov, mp3 ...etc). 
5. يمنح النظام المقترح حساب خاص مع كلمة مرور لكل مستخدم على الثبكة، فضـلاً عن امكانية تغيير كلمة المرور من قبل مدير النظام فقط وذلك للحفاظ على السرية والامان للمستخدمين.

6. يتمتع النظام بقدرته على العمل تحت عدد من انظمة التثغيل المختلفة مثل(Windows, Linux).

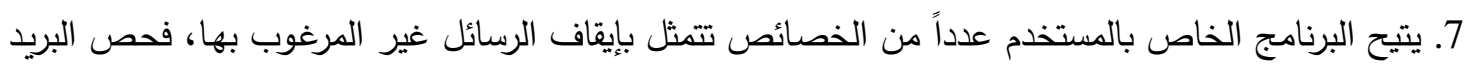

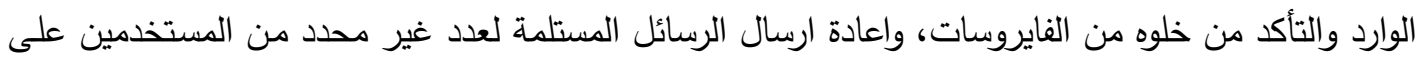

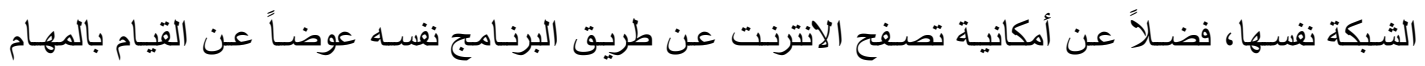
الاعتيادية للبريد الاككتروني مثل تحرير، اضافة، مسح، الرسائل.

ب. ب التوصيات استكمالاً لما سبق واعتماداً على الاستتتاجات انفة الذكر فقد تم التوصل الى عدد من التوصيات ندرجها

1. تطوير العمل بالنظام عن طريق توصيله بالثبكة الخارجية الانترنيت وتطوير البروتوكولات الخاصة بذلك.

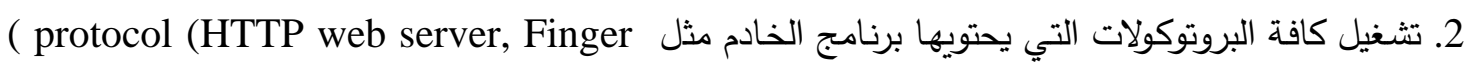
وذلك للانتقال لتقنية تصفح البريد الاككتروني من خلال متصفح الانترنيت على الثبكة، فضدلاً عن امكانية تغيير كلمة المرور من قبل المستخدم عند الضرورة. 3. ان استخدام البرمجيات ذات الترخيص (مغلوقة المصدر) يؤدي الى وجود العديد من المحددات التي تواجها الكادر التقني مثل استخدام عدد محدد من البرنامج ذاته وعدم قابلية البرنامج للعمل على اكثر من نظام فضلاملاً

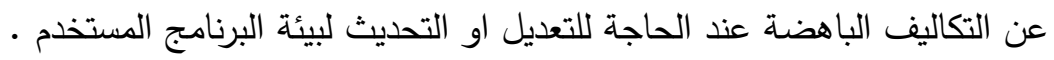

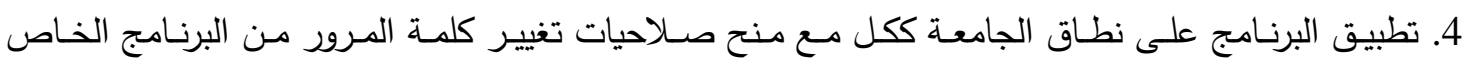

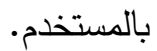

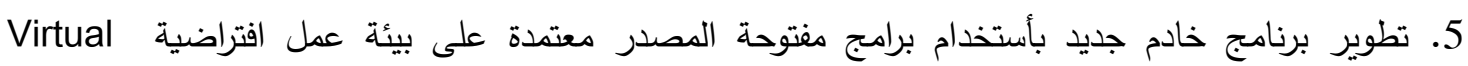
Machine (Postfix) 6. تطوير برنامج خادم للنشر والتوثيق الاكتروني عبر شبكة الجامعة باعتماد البرامج مفتوحة المصدر مثل خادم XAMPP 


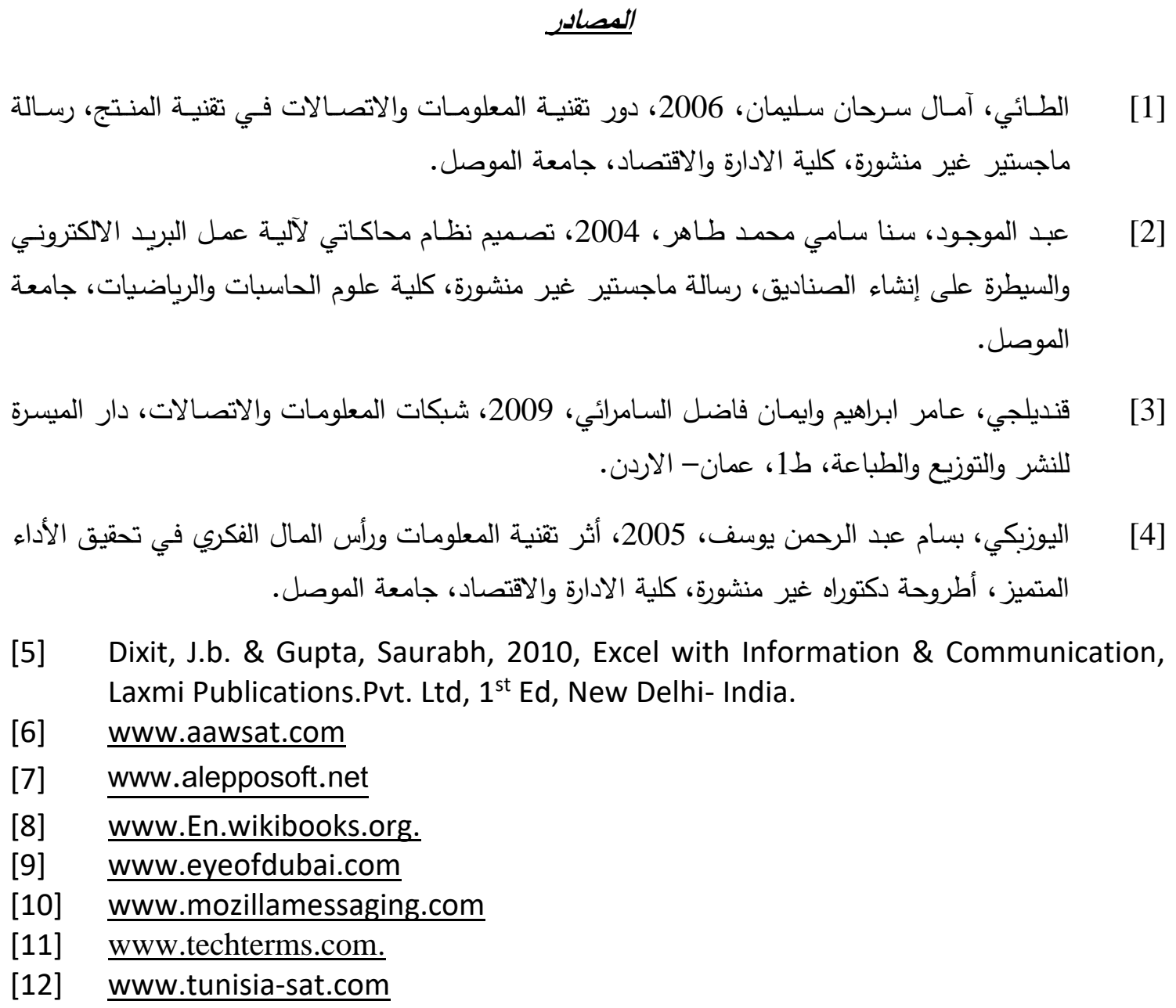

[5] Dixit, J.b. \& Gupta, Saurabh, 2010, Excel with Information \& Communication, Laxmi Publications.Pvt. Ltd, $1^{\text {st }}$ Ed, New Delhi- India.

[6] www.aawsat.com

[7] www.alepposoft.net

[8] www.En.wikibooks.org.

[9] www.eyeofdubai.com

[10] www.mozillamessaging.com

[11] www.techterms.com.

[12] www.tunisia-sat.com 